\title{
Snow spectral albedo at Summit, Greenland: measurements and numerical simulations based on physical and chemical properties of the snowpack
}

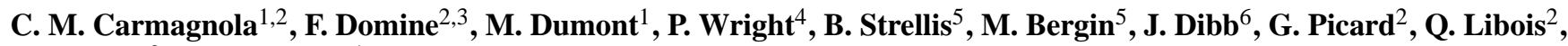 \\ L. Arnaud ${ }^{2}$, and S. Morin ${ }^{1}$ \\ ${ }^{1}$ Météo-France - CNRS, CNRM - GAME UMR 3589, Centre d'Etudes de la Neige, Grenoble, France \\ ${ }^{2}$ CNRS, UJF Grenoble, LGGE, Grenoble, France \\ ${ }^{3}$ Takuvik Joint International Laboratory, CNRS and Université Laval, Québec (QC), Canada \\ ${ }^{4}$ University of Houston, Houston (TX), USA \\ ${ }^{5}$ Georgia Institute of Technology, Atlanta (GA), USA \\ ${ }^{6}$ University of New Hampshire, Durham (NH), USA
}

Correspondence to: C. M. Carmagnola (carlo.carmagnola@meteo.fr)

Received: 29 October 2012 - Published in The Cryosphere Discuss.: 11 December 2012

Revised: 22 May 2013 - Accepted: 1 June 2013 - Published: 24 July 2013

\begin{abstract}
The broadband albedo of surface snow is determined both by the near-surface profile of the physical and chemical properties of the snowpack and by the spectral and angular characteristics of the incident solar radiation. Simultaneous measurements of the physical and chemical properties of snow were carried out at Summit Camp, Greenland $\left(72^{\circ} 36^{\prime} \mathrm{N}, 38^{\circ} 25^{\prime} \mathrm{W}, 3210 \mathrm{~m}\right.$ a.s.l.) in May and June 2011, along with spectral albedo measurements. One of the main objectives of the field campaign was to test our ability to predict snow spectral albedo by comparing the measured albedo to the albedo calculated with a radiative transfer model, using measured snow physical and chemical properties. To achieve this goal, we made daily measurements of the snow spectral albedo in the range $350-2200 \mathrm{~nm}$ and recorded snow stratigraphic information down to roughly $80 \mathrm{~cm}$. The snow specific surface area (SSA) was measured using the DUFISSS instrument (DUal Frequency Integrating Sphere for Snow SSA measurement, Gallet et al., 2009). Samples were also collected for chemical analyses including black carbon (BC) and dust, to evaluate the impact of light absorbing particulate matter in snow. This is one of the most comprehensive albedo-related data sets combining chemical analysis, snow physical properties and spectral albedo measurements obtained in a polar environment. The surface albedo was
\end{abstract}

calculated from density, SSA, BC and dust profiles using the DISORT model (DIScrete Ordinate Radiative Transfer, Stamnes et al., 1988) and compared to the measured values. Results indicate that the energy absorbed by the snowpack through the whole spectrum considered can be inferred within $1.10 \%$. This accuracy is only slightly better than that which can be obtained considering pure snow, meaning that the impact of impurities on the snow albedo is small at Summit. In the near infrared, minor deviations in albedo up to 0.014 can be due to the accuracy of radiation and SSA measurements and to the surface roughness, whereas deviations up to 0.05 can be explained by the spatial heterogeneity of the snowpack at small scales, the assumption of spherical snow grains made for DISORT simulations and the vertical resolution of measurements of surface layer physical properties. At 1430 and around $1800 \mathrm{~nm}$ the discrepancies are larger and independent of the snow properties; we propose that they are due to errors in the ice refractive index at these wavelengths. This work contributes to the development of physically based albedo schemes in detailed snowpack models, and to the improvement of retrieval algorithms for estimating snow properties from remote sensing data. 


\section{Introduction}

Surface snow is an important component of the climate system (Flanner et al., 2011). One of the most powerful drivers of climate and the main characteristic of snow-covered areas is their high albedo (i.e. the fraction of solar light that is reflected) compared to land cover types on Earth. A reduction in the snow cover will lead to increased absorption of energy that further warms the planet in what is called the snow albedo feedback (Hall, 2004). In this context, research efforts are continuing to find out more about the energy balance of snow-covered surfaces (Lemke et al., 2007), and accurately modelling snow albedo becomes of crucial importance.

Several factors influence snow albedo, starting from the index of refraction of ice (Warren and Wiscombe, 1980). In addition, the albedo depends on snow physical properties, specifically density and optically-equivalent grain size, and on the presence of impurities within the snowpack (Warren, 1982; Flanner et al., 2012). Finally, it is also affected by the angular and spectral distributions of incoming solar radiation (Warren and Wiscombe, 1980).

Snow albedo varies greatly across the solar spectrum (Warren and Wiscombe, 1980; Warren, 1982), according mainly to the spectral variations of the ice refractive index. In the visible region $(\lambda=0.40-0.75 \mu \mathrm{m})$, ice absorption is weak and the radiation can be scattered back to the atmosphere or may penetrate into the snow down to several tens of $\mathrm{cm}$. At these wavelengths, the albedo is generally above 0.9 for snow with low to moderate amounts of impurities. In the near and short-wave infrared region $(\lambda=0.75-3.0 \mu \mathrm{m})$, ice is more absorptive: at $\lambda=1.5 \mu \mathrm{m}$, for example, the incoming solar radiation is absorbed within the top few millimetres of snow and albedo values are lower than 0.1 (Warren, 1984).

Scattering and absorption of sunlight in snow are determined by the profile of the physical and chemical properties of the snowpack. Since a photon has a chance of being scattered at the air-ice interfaces and a chance of being absorbed inside the ice crystals (Gardner and Sharp, 2010), in the visible part of the spectrum, where the optical depth is greater than in the infrared and the number of interfaces crossed by a photon is large, there is a high probability of scattering and thus a high albedo. Here, precisely because of this weak ice absorption, even small amounts of absorbing impurities, such as black carbon (BC), dust and volcanic ash, can significantly reduce snow albedo (Doherty et al., 2010). The impact of these impurities on snow broadband albedo is not negligible, because they reduce albedo at wavelengths where most of the incoming solar radiation occurs. This is why they can have a large impact on the overall energy budget of the snowpack. Compared to other impurities that deposit on snow, notably dust, $\mathrm{BC}$ absorbs solar radiation most efficiently and accordingly it is an important climate forcing agent (Flanner et al., 2011). On the contrary, in the nearinfrared (NIR) region, where ice absorption is stronger, snow spectral albedo is weakly influenced by the presence of impurities and mostly determined by the snow microstructural properties. In that part of the spectrum, the solar radiation is scattered and absorbed mainly by the snow grains and the albedo is then highly sensitive to optically-equivalent snow grain size (Wiscombe and Warren, 1980; Aoki et al., 2003).

The notion of "snow grain size" has been often used to describe the snow and its interaction with the incoming solar radiation (Giddings and LaChapelle, 1961; Warren, 1982; Grenfell et al., 1994), but it has not always been well defined (Grenfell and Warren, 1999). In this study, to characterize the optically relevant size of snow grains, we use the snow specific surface area (SSA). The snow specific surface area is defined as the ratio between the area of the air-snow interface and the mass of the snow sample, and can be expressed in $\mathrm{m}^{2} \mathrm{~kg}^{-1}$ (Nolin and Dozier, 2000; Domine et al., 2007a). This variable is inversely proportional to the optical radius $\left(r_{\mathrm{opt}}\right)$, i.e. the radius of a collection of disconnected spheres featuring the same surface area/volume ratio:

$\mathrm{SSA}=\frac{3}{r_{\mathrm{opt}} \times \rho_{\text {ice }}}$,

where $\rho_{\text {ice }}$ is the density of ice. The SSA is therefore a critical characteristic of the optical properties of the snowpack and is very important for assessing its energy budget. In addition, SSA is impacted by snow metamorphism. Indeed, the overall ice-air interface area generally decreases during snow metamorphism, leading to a SSA decrease over time. The measured SSA values vary from $224 \mathrm{~m}^{2} \mathrm{~kg}^{-1}$ for diamond dust crystals (Domine et al., 2012) to less than $2 \mathrm{~m}^{2} \mathrm{~kg}^{-1}$ for melt-freeze crusts (Domine et al., 2007b). This variable can easily be measured in the field using DUFISSS (DUal Frequency Integrating Sphere for Snow SSA measurement, Gallet et al., 2009), a device allowing the rapid retrieval of snow specific surface area from infrared reflectance measurements at $1310 \mathrm{~nm}$.

Snow surface albedo is not an intrinsic property of snow, as it also depends on the spectral and angular distributions of the incoming solar radiation (Wiscombe and Warren, 1980; Yang, 2006). In particular, the albedo depends on the solar zenith angle (SZA), with larger values at grazing angles. The diffuse radiation fraction also influences the albedo, because the purely diffuse radiation results in an albedo similar to that of direct radiation with a SZA of $\sim 50^{\circ}$ over a horizontal snow surface (Wiscombe and Warren, 1980). Finally, the surface roughness can affect surface albedo by trapping radiation (which leads to lower albedo values) and by modifying the effective angle of incidence relative to a flat surface. At high zenith angles, this can have a significant impact on the broadband albedo (Zhuravleva and Kokhanovsky, 2011).

Direct ground-based measurements of snow and ice optical properties are sparse and discontinuous (Hansen and Nazarenko, 2004; Wang and Zender, 2011). The available field data cover only few areas and a small range of snow and ice types. The database is limited especially 
for remote regions such as the Arctic and Antarctic (Kondratyev and Cracknell, 1998). Meirold-Mautner and Lehning (2004), for instance, measured the transmission of light thought the snowpack at Summit. At the same location, high quality measurements of hemispherical-directional reflectance factors (HDRF) and spectral albedo were carried out by Bourgeois et al. (2006), under solar zenith angles from $49^{\circ}$ to $85^{\circ}$ and for different snow surface types. These measurements are crucial in order to improve satellite-based albedo retrievals (Wuttke et al., 2006) as well as for validating parameterizations for climate models (Ettema et al., 2009; Fettweis et al., 2011). Indeed, nowadays remote sensing algorithms to retrieve albedo and other snow properties from space (Kokhanovsky and Schreier, 2009; Roman et al., 2010; Nolin, 2011) need further evaluation. In the same way, numerical schemes of snow albedo incorporated into surface energy balance models (Pedersen and Winther, 2005; Flanner and Zender, 2006; van Meijgaard et al., 2008; Vionnet et al., 2012) can still be improved.

The seminal paper of Warren and Wiscombe (1980) ended emphasizing the need "to make simultaneous measurements of snow spectral albedo, snow grain size, soot concentration and soot size distribution." This has not proved an easy task, especially due to the difficulty of measuring the snow grain size in the field in a precise and objective manner. For example, Perovich (2007) measured the light reflection and transmission in a quasi-laboratory setting in Hanover $(\mathrm{NH}$, USA), but in this study the "snow grain size and grain shape were subjectively determined using a scale and eyepiece as well as photographs." More recently, Gallet et al. (2011) used DUFISSS to measure the snow specific surface area in the Antarctic plateau and were able to calculate the snow albedo from the vertical profiles of SSA and density. However, they had not performed chemical analysis of light-absorbing impurities and, above all, they had not taken albedo measurements directly in the field. Another open issue regarding Arctic snowpacks is the potential presence of a thin, high SSA surface layer, which could greatly affect the snow albedo. Grenfell et al. (1994), for instance, needed to invoke a thin surface layer $(0.25 \mathrm{~mm})$ with very small grains (radius of $30 \mu \mathrm{m})$ in order to reconcile their simulations with the spectral albedo measured at the South Pole. On the Greenland ice cap, the possible presence of such a layer and its effect on the albedo have not yet been investigated.

In this work, we present measurements carried out at Summit (Greenland) in May and June 2011. This site, characterized by a low impurity content within the snowpack (Hagler et al., 2007a) and by the fact that snowmelt rarely occurs during summer months (Steffen et al., 1996), is particularly suitable for studying the link between the snow physical properties and surface albedo. During our field campaign we obtained, to the best of our knowledge, one of the most comprehensive polar environment data sets combining all the complementary measurements needed for snow spectral albedo calculation. Our main purpose was to evaluate the possibility to calculate the albedo from snow properties; thus, in our analysis we did not focus on the time evolution, but we considered each albedo spectrum individually. We then compared the measured snow spectral albedo with the albedo computed from density, SSA, BC and dust profiles using the DISORT radiative transfer model (DIScrete Ordinate Radiative Transfer, Stamnes et al., 1988). The accuracy of this model to simulate the albedo was tested, examining especially the effects of impurities and investigating the properties of the surface snow layers.

\section{Instruments and methods}

\subsection{Field measurements}

\subsubsection{Location and dates}

Summit Camp is located at the peak of the Greenland ice cap $\left(72^{\circ} 36^{\prime} \mathrm{N}, 38^{\circ} 25^{\prime} \mathrm{W}\right)$, at $3210 \mathrm{~m}$ a.s.l. (http://www. summitcamp.org/). Summit is a research station that supports a diversity of scientific research, including for instance investigations of air-snow interactions (Albert and Shultz, 2002; Dibb and Fahnestock, 2004; Dibb et al., 2007). Moreover, it is the site of one of the 18 automatic weather stations (AWS) covering the Greenland ice-sheet that make up the Greenland Climate Network (Steffen et al., 1996).

At Summit snowfall can occur in all seasons (Albert and Hawley, 2000), but the accumulation rate, about $65 \mathrm{~cm} \mathrm{yr}^{-1}$, is not seasonally uniform, since more new snow falls during the summer months (Dibb and Fahnestock, 2004). In addition, the temperature and wind conditions change dramatically during the year (Albert and Shultz, 2002). These variations in meteorological conditions strongly affect the microstructure of surface snow and account for the great variability of the snowpack (Albert and Shultz, 2002). Low amounts of impurities are present in the snow, BC and dust being the types with the strongest effect on the albedo (Warren and Wiscombe, 1980; Hagler et al., 2007a).

Figure 1 shows meteorological data collected by instruments placed on the Summit AWS. All reported measurements were acquired in May and June 2011. During that period, the air temperature, measured at $3.7 \mathrm{~m}$ above snow with a type-E thermocouple (estimated accuracy of $0.1{ }^{\circ} \mathrm{C}$ ), was always negative. No liquid water was ever found in the snowpack. The wind speed data recorded by a RM Young propeller-type vane (estimated accuracy of $0.1 \mathrm{~m} \mathrm{~s}^{-1}$ ) indicate that there were no strong wind events, except on 4 June (with a wind speed higher than $11 \mathrm{~ms}^{-1}$ ). The short-wave incoming radiation was measured using a Li-Cor photodiode with a nominal accuracy of $15 \%$. Values at 11:00 local time (LT hereafter), when our daily albedo measurements were performed, ranged between about 300 and $800 \mathrm{Wm}^{-2}$. Lastly, the snow height, monitored by a Campbell SR-50 with $1 \mathrm{~mm}$ precision, shows that, despite frequent small 


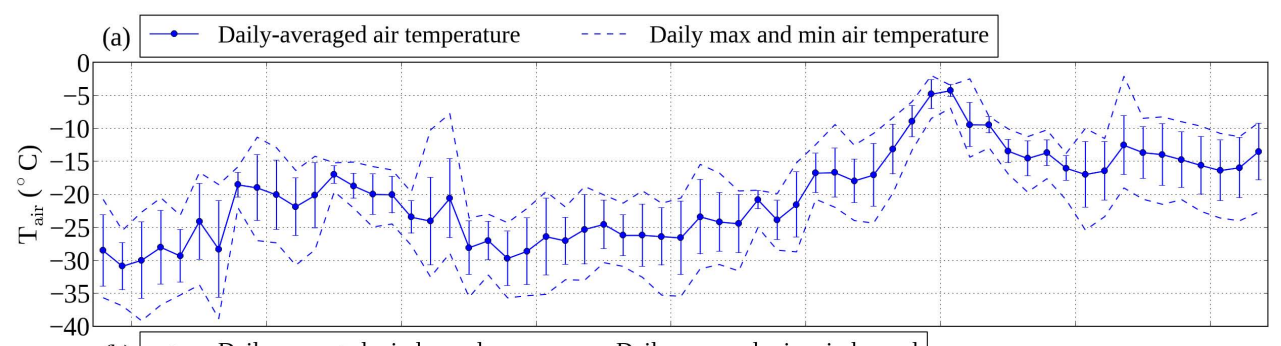

(b) $\rightarrow \quad$ Daily-averaged wind speed $\quad \cdots \quad$ Daily max and min wind speed

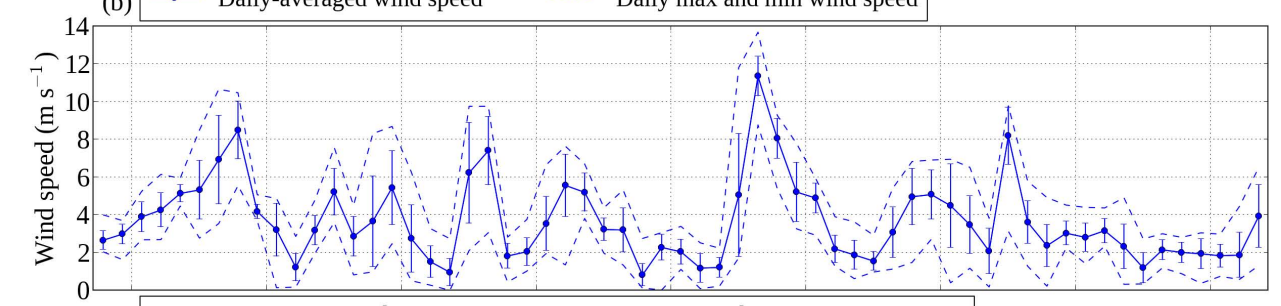

(c) $\longrightarrow$ SW incoming radiation $\longrightarrow$ SW incoming radiation at 11:00 a.m. LT
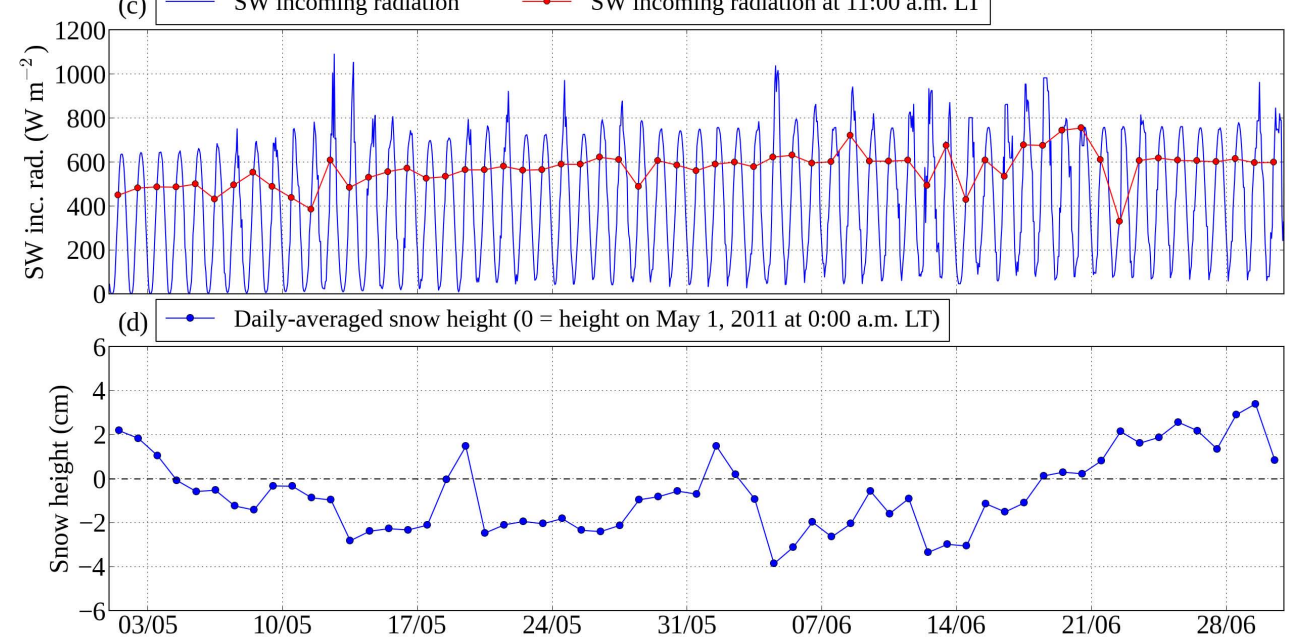

Fig. 1. Meteorological data collected in May and June 2011 by instruments placed on the Summit AWS. (a) Daily average (solid line) and daily maximum and minimum (dashed lines) air temperature at $3.7 \mathrm{~m}$ above snow. (b) Daily average (solid line) and daily maximum and minimum (dashed lines) wind speed at $3.7 \mathrm{~m}$ above snow. (c) Hourly short-wave incoming solar radiation; values at 11:00 LT are also highlighted. (d) Daily averaged snow height since 1 May 2011 at 00:00 LT. Error bars in the top two panels correspond to one standard deviation.

amounts of precipitation, no significant accumulation occurred.

Additional snow albedo spectra were acquired at the Col de Porte (CdP) field site in March 2012. The aim of these measurements was to test the influence of the snowpack properties and of the measurement device on some discrepancies between model predictions and observations found in the infrared region (at 1430 and around $1800 \mathrm{~nm}$ ). The CdP station, located in the French Alps at an elevation of $1325 \mathrm{~m}$ a.s.l., has been used for over $50 \mathrm{yr}$ for snow research and records snow and meteorological variables at an hourly time resolution (Morin et al., 2012). There, we performed snow physical properties and albedo measurements, but no chemical analyses.

\subsubsection{Overall strategy}

The measurements were carried out in the Summit clean air sector, an area of undisturbed snow located south-east of the base. During our field campaign we measured, almost every day at 11:00 LT, the downwelling and upwelling spectral irradiance (Sect. 2.1.3). Once these measurements were completed, at about 11:30LT, we dug a pit at the same spot to measure the vertical profile of the snow physical properties, including density and specific surface area (Sect. 2.1.4). Finally, we collected samples for chemical analysis, to estimate the $\mathrm{BC}$ and dust concentrations in snow (Sect. 2.1.5). Every day the sampling location was moved about $5 \mathrm{~m}$ away to avoid contamination from previous days' activities. In addition to regular vertical profiles, during periods of intensive sampling, we also measured simultaneously surface snow 


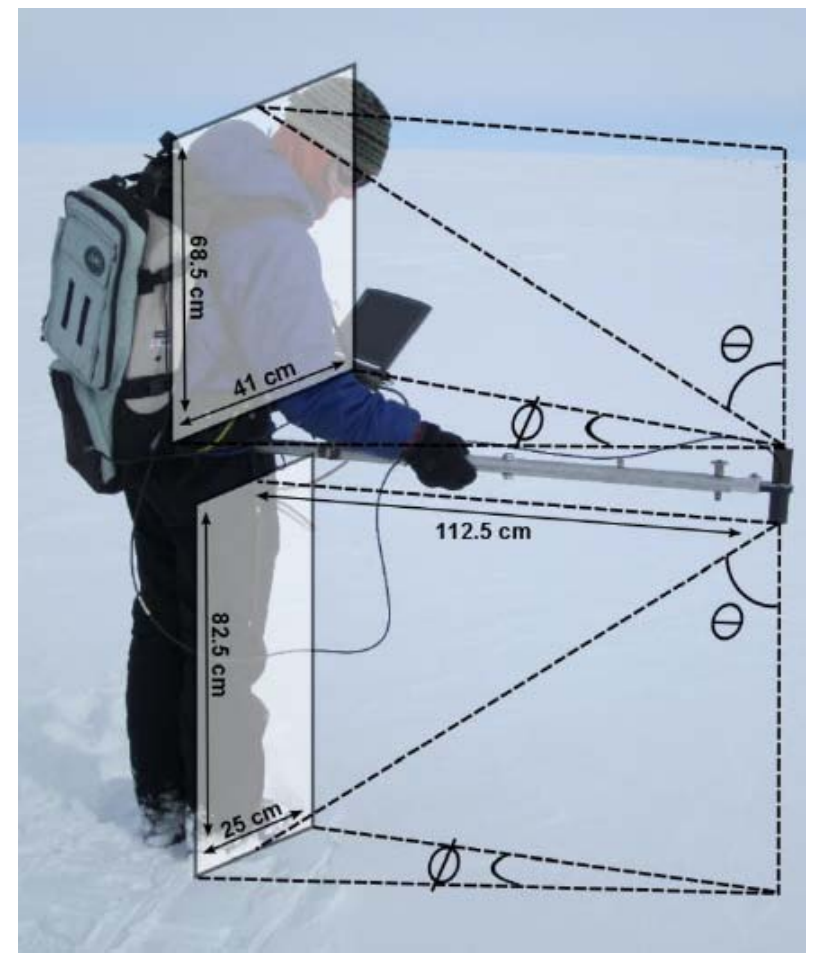

Fig. 2. Set-up of the ASD spectroradiometer during data acquisition. The solid angle viewed by the sensor is corrected through the angles $\theta$ and $\phi$, which are used to compute $C_{\uparrow}$ and $C_{\downarrow}$ to take into account the presence of the observer.

SSA and albedo at several spots in order to study the spatial variability of these variables (Sect. 2.1.6).

\subsubsection{Radiation measurements}

\section{Raw data}

Spectral albedo measurements were obtained using an ASD FieldSpec Pro spectroradiometer (see Fig. 2). This instrument has a spectral range of 350 to $2200 \mathrm{~nm}$, with a spectral resolution ranging from $3 \mathrm{~nm}$ in the $\mathrm{UV}$ to $12 \mathrm{~nm}$ in the IR. It was equipped with a remote cosine receptor (RCR), a lightdiffusing fore optic used for upwelling and downwelling flux measurements. The albedo was then simply computed by making the ratio of these fluxes. The downwelling diffuse radiation was also measured by manually shielding the spectroradiometer receptor from direct sunlight.

Four repeated measurements were made at each location. The raw data were carefully examined, removing those affected by errors. Specifically, we have removed individual albedo measurements which were greater than 1 in the $\mathrm{UV} / \mathrm{visible}$ range, displayed instrumental error on the first detector (wavelengths $<976 \mathrm{~nm}$ ), or were obvious outliers compared to the three other measurements, which otherwise showed high repeatability. The outlier data were clearly influenced by measurements made during periods of variable sky conditions, such as passing clouds, or errors in instrumental level. All the measurements which met the quality criteria listed above were retained and averaged, obtaining a single spectral albedo curve for each date. Standard deviation values are lower than $0.3 \%$ of the albedo over the whole spectrum, except around $1825-1900 \mathrm{~nm}$, where there is no reliable signal due to a low signal/noise ratio.

\section{RCR response}

The angular response of the RCR used during our field campaign at Summit was characterized in laboratory, in order to evaluate its deviation from an ideal cosine response and to quantify the impact of this deviation on the measured fluxes. For this purpose, the RCR was mounted on a optical table allowing us to control its angular position with respect to a fixed light source. Intensity measurements for zenith angles varying from $-90^{\circ}$ to $+90^{\circ}$ were performed using the ASD device. Then, the RCR was rotated by $90^{\circ}$ around its symmetry axis to change the azimuth angle and the calibration curve in zenith angle was acquired again. Relative intensities normalized by $I\left(0^{\circ}\right)$ were compared to the true cosine response, allowing us to compute the cosine collector fractional deviation $\left(\varepsilon_{\lambda}\right)$ as a function of the zenith angle of the incident light $\left(\theta_{S}\right)$ :

$\varepsilon_{\lambda}\left(\theta_{S}\right)=\frac{\frac{I\left(\theta_{S}\right)}{I\left(0^{\circ}\right)}-\cos \theta_{S}}{\cos \theta_{S}}$.

We chose to normalize the ASD signal by $I\left(0^{\circ}\right)$ following other studies (Lubin and Vogelmann, 2011). The measured intensity could have also been normalized by other factors such as the intensity integrated over the hemisphere, which would affect the values of $\varepsilon_{\lambda}$ but not their variations with the zenith angle. Nevertheless, since we are dealing with albedo and not absolute fluxes, the choice of this normalization constant has no influence on the final corrections of this study.

Figure 3 shows the RCR measured response at $500 \mathrm{~nm}$. The values obtained for the two azimuth angles are represented by blue and red markers. The RCR angular response is consistent with what Lubin and Vogelmann (2011) reported in their study. In the spectral range 400-1000 nm, our RCR deviation from a perfect cosine response does not exceed 10$14 \%$. Lubin and Vogelmann (2011) reported that the maximum deviation given by the constructor is approximately $10 \%$. A similar behaviour was also described by Meywerk and Ramanathan (1999). At $1600 \mathrm{~nm}$, the RCR deviation between $0^{\circ}$ and $75^{\circ}$ is lower than $5 \%$, whereas Lubin and Vogelmann (2011) reported a deviation lower than $2 \%$, even though in their case the investigated range of zenith angles was shorter $\left(0^{\circ}-60^{\circ}\right)$. In the following, to implement the RCR correction of the albedo we took the mean between cosine deviations measured at both azimuth angles. 


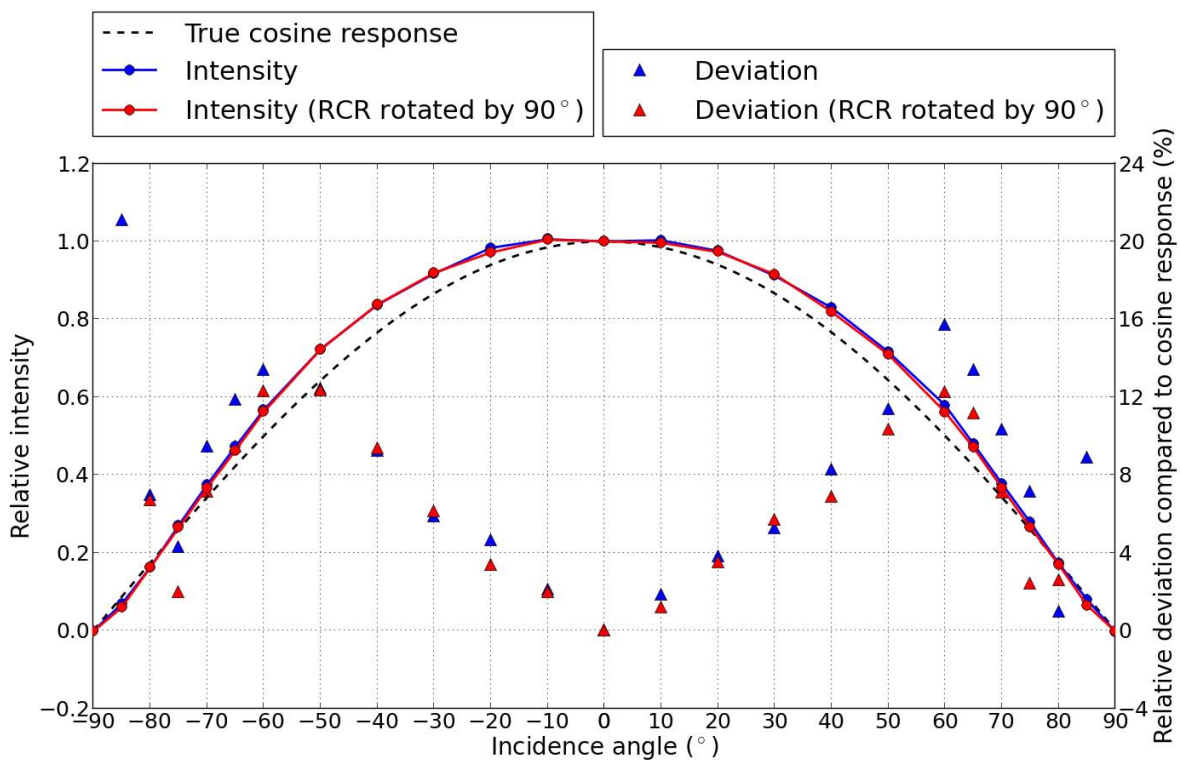

Fig. 3. Angular response of the RCR sensor at $500 \mathrm{~nm}$, for incidence angles ranging from $-90^{\circ}$ to $90^{\circ}$. The true cosine response is represented by the dashed black line and the relative intensities normalized by $I\left(0^{\circ}\right)$ are represented by blue circles. Blue triangles represent absolute values of the deviation of the measured response from a true cosine response (see Eq. 2). The RCR response has also been measured after rotating the sensor along its axis by $90^{\circ}$ (red circles and triangles).

\section{Corrections of spectral albedo: methods}

Field measurements of spectral albedo can be influenced by various artefacts, some of which were addressed in our data processing. This concerns the already discussed RCR deviation from a pure cosine response (see Eq. 2), but also the field-of-view obstruction due to the presence of the observer and the fact that these previous artefacts need to be corrected in light of the fact that the upwelling and downwelling irradiances are not isotropic. In particular, assuming that the reflected radiation is isotropic may lead to errors, depending mostly on the incidence and measuring angles (Bourgeois et al., 2006); a strong forward scattering occurs, for instance, at high solar zenith angles, especially at NIR wavelengths (Odermatt et al., 2005; Dumont et al., 2010). Let $F_{\text {true, } \lambda}$ be the real flux and $F_{\text {meas, } \lambda}$ the measured flux associated to radiance $F(\theta, \phi, \lambda)$. The measured flux can be expressed as follows:

$F_{\text {meas }, \lambda}=\int_{0}^{\frac{\pi}{2}} \int_{\phi \lim }^{2 \pi} F(\theta, \phi, \lambda) \frac{I(\theta)}{I\left(0^{\circ}\right)} \sin \theta d \theta d \phi$.

In Eq. (3), all the above-mentioned artefacts influencing the spectral albedo are considered. The normalized intensity measured by the RCR, $I(\theta) / I\left(0^{\circ}\right)$, describes the effect of the deviation of the RCR from a true cosine response; in case of a perfect response, this factor is equal to $\cos (\theta)$. The reduction of the field of view due to the presence of the observer is taken into account by changing the range of integration over $\phi$; in our case, the field of view is obstructed from 0 to $\phi_{\text {lim. }}$. Lastly, we define $H(\theta, \phi, \lambda)$, which describes the angular distribution of the deviation between $F_{\text {meas }, \lambda}$ and $F_{\text {true }, \lambda}$ :

$H(\theta, \phi, \lambda)=\pi \frac{F(\theta, \phi, \lambda)}{F_{\text {true }, \lambda}}$.

The latter expression allows us to reformulate Eq. (3) as

$F_{\text {meas }, \lambda}=F_{\text {true }, \lambda} \int_{0}^{\frac{\pi}{2}} \int_{\phi \lim }^{2 \pi} \frac{H(\theta, \phi, \lambda)}{\pi} \frac{I(\theta)}{I\left(0^{\circ}\right)} \sin \theta d \theta d \phi$.

The downwelling irradiance $F_{\text {true, } \lambda}^{\downarrow}$ can be split into diffuse and direct components. If we call $F_{\lambda \text {,dif }}^{\downarrow}$ the measured downwelling diffuse radiation, assumed isotropic, and $F_{\lambda \text {,dir }}^{\downarrow}$ the downwelling direct radiation, then the corrected downwelling irradiance can be written as

$F_{\text {true }, \lambda}^{\downarrow}=C_{\lambda} C_{\downarrow} F_{\lambda, \text { dif }}^{\downarrow}+\frac{F_{\lambda, \text { dir }}^{\downarrow}}{1+\varepsilon_{\lambda}\left(\theta_{S}\right)}$.

$C_{\lambda}$ is a correction factor accounting for the RCR deviation (Grenfell et al., 1994):

$C_{\lambda}=\frac{0.5}{\int_{0}^{1} \mu\left(1+\varepsilon_{\lambda}(\mu)\right) d \mu}$,

where $\mu=\cos \theta$. The coefficient $C_{\downarrow}$, here assumed independent of $\lambda$, is derived from the solid angle viewed by the sensor calculating the exact projected area of the observer with 


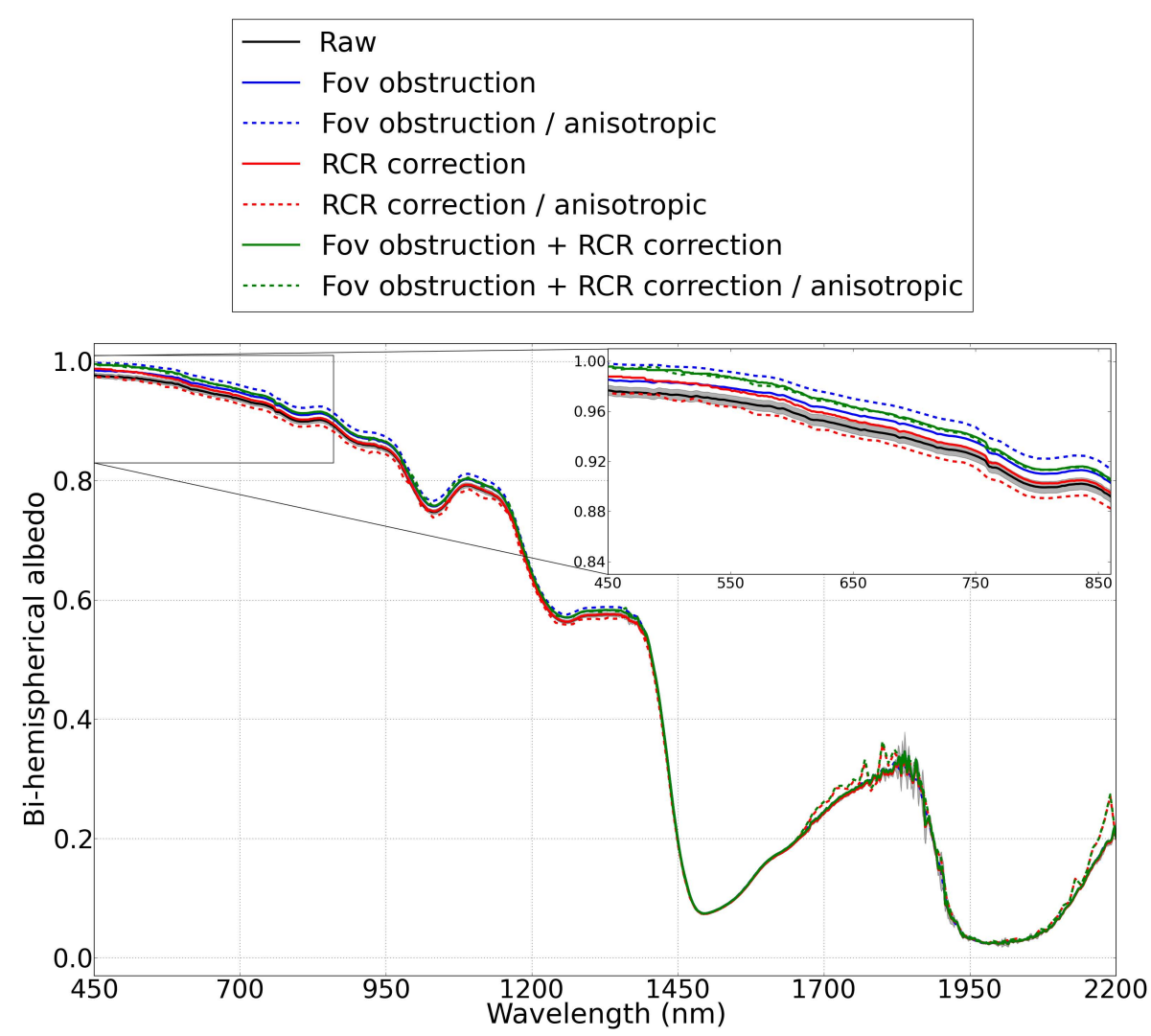

Fig. 4. Impact of corrections on the measured spectral albedo for 20 June 2011. Black line refers to raw ASD data obtained by averaging 4 daily spectra; the resulting standard deviation is represented in grey. The effect of the field of view obstruction by the observer is represented by blue curves, the impact of cosine collector deviation is represented by red curves and the total correction is represented by green curves. In each case, dashed lines show the effect of taking into account the anisotropy of reflected radiation on the correction of spectral albedo (see Eq. 9.)

a $50^{\circ} \mathrm{SZA}$ (see Fig. 2). The observer is considered perfectly absorbing, even if this assumption is not always realistic, especially at NIR wavelengths.

For the upwelling irradiance $F_{\text {true, } \lambda}^{\uparrow}$, the relationship between measured and corrected fluxes can be easily derived from Eq. (5):

$$
F_{\text {true }, \lambda}^{\uparrow}=\frac{F_{\lambda, \text { dif }}^{\uparrow}}{\int_{0}^{\frac{\pi}{2}} \int_{\phi_{\text {lim }}}^{2 \pi} \frac{H(\theta, \phi, \lambda)}{\pi} \frac{I(\theta)}{I\left(0^{\circ}\right)} \sin \theta d \theta d \phi},
$$

where $F_{\lambda \text {,dif }}^{\uparrow}$ is the measured upwelling diffuse radiation.

Therefore, the corrected albedo can be calculated from the measured fluxes combining Eq. (6) and Eq. (8):

$\alpha_{\text {true }, \lambda}=$

$$
\frac{F_{\lambda, \text { dif }}^{\uparrow}}{\left(C_{\lambda} C_{\downarrow} F_{\lambda, \text { dif }}^{\downarrow}+\frac{F_{\lambda, \text { dir }}^{\downarrow}}{1+\varepsilon_{\lambda}\left(\theta_{S}\right)}\right) \int_{0}^{\frac{\pi}{2}} \int_{\phi_{\lim }}^{2 \pi} \frac{H(\theta, \phi, \lambda)}{\pi} \cdot \frac{I(\theta)}{I\left(0^{\circ}\right)} \cdot \sin \theta d \theta d \phi} .
$$

Finally, assuming that the reflected radiation is isotropic $(H(\theta, \phi, \lambda) \equiv 1)$, Eq. (9) reduces to

$$
\alpha_{\text {true_iso, } \lambda}=\frac{C_{\lambda} C_{\uparrow} F_{\lambda, \text { dif }}^{\uparrow}}{C_{\lambda} C_{\downarrow} F_{\lambda, \text { dif }}^{\downarrow}+\frac{F_{\lambda, \text { dir }}^{\downarrow}}{1+\varepsilon_{\lambda}(\theta)}} .
$$

Equation (10) is analogous of Eq. (3) in Grenfell et al. (1994), with the addition of two coefficients, $C_{\uparrow}$ and $C_{\downarrow}$, accounting for the field of view obstruction due to the presence of the observer.

\section{Corrections of spectral albedo: impact on our measurements}

Figure 4 shows the impact of the corrections described above (obstruction of the field of view and RCR correction) on the measured spectral albedo, along with the effect of taking into account or not the anisotropy of reflected radiation. Spectra in Fig. 4 refer to 20 June; all other dates display the same behaviour. We started by assuming an isotropic reflectance. Then, in order to correct the albedo for the field of view 
obstruction due to the presence of the observer, we calculated the correction factors $C_{\uparrow}$ and $C_{\downarrow}$ of Eq. (10). In our case, these coefficients are equal to 1.0133 and 1.0157 , respectively. The resulting difference between corrected albedo (solid blue curve in Fig. 4) and raw albedo is less than 0.01 over the entire spectrum. Regarding the impact of the RCR response, the albedo corrected taking into account the cosine collector deviation from a true cosine response (solid red curve in Fig. 4) differs from the ASD raw signal by about $1 \%$ in the visible region.

In order to estimate the effect of anisotropy, we used the measured anisotropy factors $R(\theta, \phi, \lambda)$ from Dumont et al. (2010) at an incidence angle of $60^{\circ}$. For the sake of simplicity and in the absence of measured spectral values of the hemispherical-directional reflectance factor, $R$ values were used as a surrogate for the normalized HDRF $(R \equiv H)$. This means that we considered snow illuminated by natural light as being as anisotropic as snow illuminated by a collimated light at a $60^{\circ}$ incidence angle. If we only correct for the obstruction of the field of view by the observer (blue curves in Fig. 4), taking into account the anisotropy gives albedo values slightly higher, at visible and NIR wavelengths, than those obtained by assuming an isotropic reflectance. The RMSD (root mean square deviation) between these two curves is 0.0102 in the range $450-1400 \mathrm{~nm}$. If we only correct for the RCR deviation from a pure cosine response (red curves), the effect on the albedo is the opposite: between 450 and $1400 \mathrm{~nm}$, albedo accounting for the fact that snow reflection is anisotropic is lower than that computed by assuming an isotropic reflection (RMSD of 0.0108). Finally, the combined effects of anisotropy on both field of view obstruction and cosine response (green curves) compensate each other, leading to small differences between albedo with isotropic and anisotropic corrections (RMSD of 0.0026). Around 1800 and $2100 \mathrm{~nm}$, albedo values are affected by the low signal/noise ratio of the RCR calibration. If we exclude these two spectral bands, the estimated error of assuming an isotropic reflectance ranges from 0.2 to $0.4 \%$. These values are of the same order of magnitude of the estimated accuracy of our spectral albedo measurements. In the following, in the absence of knowledge on its angular distribution, the measured upwelling diffuse radiation will be considered isotropic.

\section{Additional albedo measurements}

Albedo measurements were also performed at Col de Porte (see Sect. 2.1.1) using another spectroradiometer, the SVC HR1024 (http://www.spectravista.com/HR1024.html). This instrument was equipped with a $2 \mathrm{~m}$ optical fibre and an integrating sphere, which eliminates the need of the RCR. The sensor, placed approximately $50 \mathrm{~cm}$ above the snow surface, has a spectral resolution between 3.5 and $9.5 \mathrm{~nm}$. The nomi- nal accuracy of the measured radiance varies from $4 \%$ in the visible up to $7 \%$ at the near-infrared wavelengths.

\subsubsection{Profiles of the snow physical properties}

Trenches were dug exposing a planar, vertical snow face from the surface down to about $80 \mathrm{~cm}$. Their study allowed the complete characterization of the surface layer properties and was done in several steps, following Fierz et al. (2009). First of all, we identified the snow layers and determined their depth below the surface and their thickness. The hardness was estimated through the conventional hand test, assigning to each layer a value between 1 (for very soft snow, such as surface hoar) and 5 (for very hard snow, such as ice crusts). We subsequently identified the dominant grain types in each layer, examining the snow, gently scraped with a plastic card, with a hand lens. We determined in this way the size and the shape of the snow crystals, according to the international classification for seasonal snow on the ground (Fierz et al., 2009). The density was measured by sampling the snow with a $250 \mathrm{~cm}^{3}$ rectangular steel cutter (Fierz et al., 2009; Conger and McClung, 2009). Samples obtained were weighed on a scale to retrieve the snow density with a $\pm 10 \%$ accuracy. The vertical resolution of our density measurements was about $4 \mathrm{~cm}$.

We measured the snow specific surface area using the DUFISSS device (Gallet et al., 2009), whose working principle relies on the relationship between the hemispherical reflectance of snow at $1310 \mathrm{~nm}$ and its SSA (Domine et al., 2006; Matzl and Schneebeli, 2006; Painter et al., 2006). For the mean density and SSA values we found during our campaign, the penetration depth of the $1310 \mathrm{~nm}$ radiation is of the order of $1 \mathrm{~cm}$ (Gallet et al., 2011). Thus, the retrieved SSA can be considered as a weighted average over about a $1 \mathrm{~cm}$ depth. The estimated accuracy of SSA measurements is $\pm 10 \%$ (Gallet et al., 2009). DUFISSS requires the sample to be prepared and presented to the instrument. For sampling, a special tool was used to take a cylindrical snow core, which was pushed with a piston into the sample holder $(6.3 \mathrm{~cm}$ in diameter and $3 \mathrm{~cm}$ thick). The snow sticking out of the sample holder was then shaved off with a sharp spatula and small particles generated by shaving were brushed off. Great care was taken to handle the surface snow layers, first because they can evolve rapidly during events such as snowfall, blowing snow, rime or surface hoar formation and secondly because their effect on albedo is greatest. For the top-cm SSA measurements we therefore followed a different procedure: in order to be sure to measure the very surface layer, the snow sticking out of the sampler was not shaved off but gently compacted. Previous tests revealed that such handling does not affect the IR reflectance (Gallet et al., 2009). Given that the samples taken were $3 \mathrm{~cm}$ high, sampling on 3 adjacent spots about $20 \mathrm{~cm}$ apart allowed SSA measurements with a $1 \mathrm{~cm}$ vertical resolution. This was done for the top $10 \mathrm{~cm}$, whereas below that a 2 to $4 \mathrm{~cm}$ resolution was 
used. Overall, we obtained a total of 25 to 45 values along the whole vertical wall of the pit.

\subsubsection{Chemical analyses}

Daily surface snow samples were collected in the clean air sector of the camp for analyses of both elemental (EC) and organic (OC) carbon as well as dust particles. The OC and EC sample collection and analyses followed the protocol described by Hagler et al. (2007a,b). In summary, precleaned glass bottles were used to collect about 101 of the top-most $1-3 \mathrm{~cm}$ of surface snow from the clean air sector each day. The snowmelt water samples were then filtered through quartz fiber filters that were sealed in airtight, bakedaluminum foil petri dishes and analysed at Georgia Tech using the NIOSH thermal/optical transmittance (TOT) method (Birch and Cary, 1996).

A wide range of elements was also measured, and of particular relevance to this work are the major crustal elements ( $\mathrm{Al}, \mathrm{Ca}, \mathrm{K}, \mathrm{Fe}, \mathrm{Na}, \mathrm{Mg}$, and $\mathrm{Si}$ ), which were used to estimate the total dust concentration. Duplicate samples were obtained by sampling the top $1-3 \mathrm{~cm}$ of snow using precleaned, acid washed polyethylene bottles. Analyses were conducted using a high-resolution ICP-MS. The samples were acidified with ultra-high purity $16 \mathrm{~N}$ nitric acid just prior to analyses. Field blanks were also analysed and used to determine both blank levels and detection limits.

\subsubsection{Spatial variability of surface snow physical properties}

The spatial variability of the surface snow properties at Summit is mostly due to the effect of wind (Albert and Shultz, 2002). Changes in wind speed and direction strongly impact the snow surface characteristics. Within a few metres, the surface layer can be made of precipitation particles, rime, surface hoar crystals or wind-transported snow particles, that are present in the form of small, closely packed grains. In order to quantify this horizontal variability, we made several spatial surveys. On 15 May, for example, spectral albedo and SSA were simultaneously measured at a chosen spot and then $1,4,8,12$ and $16 \mathrm{~m}$ away in the four cardinal directions. Results for the surface SSA are presented in Sect. 3.1 and justify our choice to carry out daily albedo-SSA measurements at the very same spot.

\subsection{Numerical modelling}

In this section, we describe the approach followed to simulate the snow albedo from the physical properties of the snowpack and from the characteristics of the solar irradiance. The implementation of the impurities into the model is also described.

\subsubsection{Simulations of snow albedo}

Simulations of snow albedo were run using the DISORT radiative transfer model (Stamnes et al., 1988). Mie theory (Mie, 1908) was used for computing the single scattering properties of snow, namely the absorption and extinction coefficients and the moments of the single scattering phase function. The application of Mie theory assumes that snow grains are modelled as a collection of individual spheres. This assumption has been discussed in many previous studies, e.g. Warren and Wiscombe (1980), Grenfell and Warren (1999), Kokhanovsky and Zege (2004) and Dumont et al. (2010). These studies revealed that the error implied by the spherical assumption cannot be neglected if the aim is to model the angular distribution of the radiation reflected by snow; in this case, taking into account the real shape of the snow grains is critical. However, the spherical assumption is acceptable to model only the bi-hemispherical reflectance of snow, as in the present study (Grenfell and Warren, 1999). Moreover, this approach is consistent with the assumption made by DUFISSS for retrieving SSA from reflectance at $1310 \mathrm{~nm}$. The model needs as input the ice optical refractive index, which primarily depends on wavelength. We used the most recent compilation of this index presented in Warren and Brandt (2008).

DISORT allows to simulate the optical properties of a plane-parallel multilayer snowpack. Considering the penetration depth of the solar radiation (several tens of $\mathrm{cm}$ in the visible wavelengths), we used the detailed stratigraphy of the upper $10 \mathrm{~cm}$ and we discretized the vertical profile of the snow physical properties on a $1 \mathrm{~cm}$ vertical grid. For density, we assigned to each numerical layer the closest measured value. The thickness of the bottom layer was set to $1 \mathrm{~m}$, in order to mimic a semi-infinite snowpack. Tests were conducted to compare the albedo simulated using measurements down to more than $10 \mathrm{~cm}$. The discrepancies between the albedo modelled using either the first 10 or $20 \mathrm{~cm}$ are insignificant (less than 0.001), meaning that the first $10 \mathrm{~cm}$ were enough to simulate snow albedo. In all these simulations, the snow grain size distribution was assumed to be log-normal, with a geometric standard deviation $\sigma=1.6$, to reduce biases due to discretization and resonance effects (Gallet et al., 2009). In any case, the reflectance simulated by DISORT depends only slightly on the exact distribution chosen (Gallet et al., 2009). The angular characteristics of the incident radiation are also needed to be able to compare the simulated and the measured albedo. Consequently, the solar zenith angle at the time of the albedo measurements was given as input to DISORT, together with the measured, spectrally resolved fraction of diffuse radiation.

The simulations were run with a wavelength step of $10 \mathrm{~nm}$, which is a good compromise between the computational cost and the possibility to compare the simulated albedo with the measured one, the spectral sampling of the ASD varying from 3 to $12 \mathrm{~nm}$ depending on the spectral range considered. 


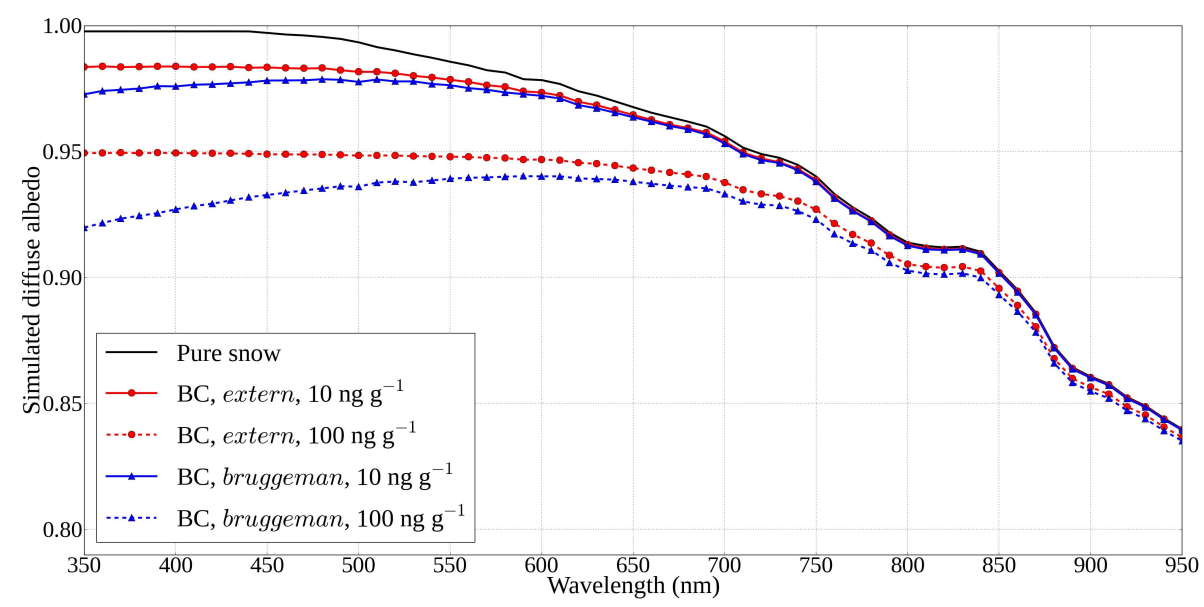

Fig. 5. Diffuse albedo of a semi-infinite snowpack with SSA $=35 \mathrm{~m}^{2} \mathrm{~kg}^{-1}$, simulated with DISORT from 350 to $950 \mathrm{~nm}$. The curves correspond to different assumptions of the snow-BC mixture: black line for pure snow, red circles for external mixture with constant radius (extern) and blue triangles for internal mixture with small grains (bruggeman). For each assumption, the solid line is for a BC content of $10 \mathrm{ng} \mathrm{g}^{-1}$ and the dashed line is for a BC content of $100 \mathrm{ngg}^{-1}$.

\subsubsection{Impurities modelling}

The impurity content can significantly impact snow albedo in the visible wavelengths (Wiscombe and Warren, 1980). In this study we consider only two types of impurities, black carbon and dust. Black carbon has proven to be the most efficient absorber in snow (Flanner et al., 2012), but its content in Summit snowpack is low, the highest value given in the literature being 1.5-2 $\mathrm{ng} \mathrm{g}^{-1}$ (Hagler et al., 2007a; Doherty et al., 2010). Dust is less absorptive, but its concentration at Summit is considerably higher than that of $\mathrm{BC}$, at least $46 \mathrm{ng} \mathrm{g}^{-1}$ (Steffensen, 1997). All the other impurities that we did not take into account, such as brown carbon and organics, are less absorbing than $\mathrm{BC}$ and less concentrated than dust; thus, also their impact on the albedo is less significant.

Several assumptions could be made to include the impurities in the snowpack. The impurities can be considered as external mixtures, i.e. outside the snow grains, or as internal mixtures, i.e. inside the snow grains (Flanner et al., 2012). They can also have different size distributions. In this study, we tested two assumptions: (i) external mixture with a constant radius for the impurities and (ii) internal mixture in the approximation of inclusions smaller than the wavelengths considered, i.e. Bruggeman formulation (Chýlek et al., 1983b). In the case of an external mixture, the Mie theory is used to derive independently the single scattering properties of ice and impurity; the optical properties of the mixture are the weighted average of the properties of the two media. In the case of an internal mixture, the dielectrical constant of the medium made of ice and impurities is calculated solving a second degree polynomial equation, following the theory of Chýlek et al. (1983a,b) also detailed in Flanner et al. (2012). The Bruggeman formulation, as well as other effective media approximations for computing the refractive index of an internal mixture of ice and impurity, is only applicable when inclusions are smaller or comparable to the wavelength (Flanner et al., 2012). This condition is met by most BC particles, but not by dust. Consequently, dust inclusions were modelled as external mixtures, following the assumption (i). On the contrary, assumption (ii) was applied to $\mathrm{BC}$ impurities, since recent studies suggest that a large portion of BC in surface snowpack may reside within ice grains (Flanner et al., 2012). Figure 5 shows that the Bruggeman formulation has a stronger impact on the simulated albedo than the external mixture assumption. Using the Bruggeman formulation thus provides an upper limit of the effect of $\mathrm{BC}$ on albedo.

The physical and optical properties of BC have been chosen following Flanner et al. (2012). The density of BC particles was set to $1270 \mathrm{~kg} \mathrm{~m}^{-3}$ and their effective radius was considered as being $95 \mathrm{~nm}$. This value is lower than the range of wavelengths considered, ensuring the applicability of assumption (ii). In addition, this choice guarantees that the Bruggeman formulation gives effective refractive indices close to those calculated using other $\mathrm{BC}$ size distributions (Fig. 3 in Flanner et al., 2012). The BC refractive indices were calculated as a function of wavelengths following Eqs. (13) and (14) in Flanner et al. (2012). For the dust grains, we used an external mixture with a constant radius of $2 \mu \mathrm{m}$ and a density of $2500 \mathrm{~kg} \mathrm{~m}^{-3}$ (Bergin et al., 1995). The dust refractive indices were taken from Balkanski et al. (2007), considering a mixture with a hematite content of $1.5 \%$ in volume. Since dust and BC contents were measured only in the upper $1-3 \mathrm{~cm}$ of the snowpack, we did not have any information on the impurity amounts further down. Thus, we have implemented the impurity concentrations in two different ways: using the daily measured impurity content either for the whole vertical profile or only for the first 


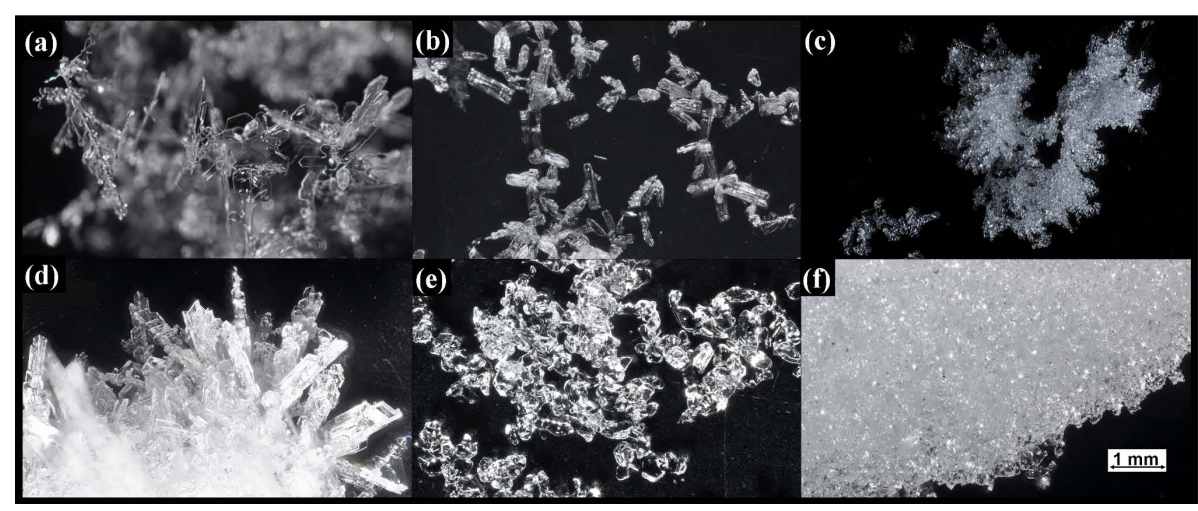

Fig. 6. The main snow types observed at Summit in May and June 2011, from stratigraphic inspections down to about $80 \mathrm{~cm}$ : (a) stellar dendrites (PPsd), (b) columns (PPco), (c) rime (PPrm), (d) surface hoar (SH), (e) faceted rounded particles (RGxf), and (f) wind-packed particles (RGwp). All pictures were taken in the Summit clean air sector between 15 May and 20 May.

$2 \mathrm{~cm}$, using the mean values over the entire field campaign below that depth. Since we found that both these approaches gave almost the same results, hereinafter we present only results obtained using the first one.

\subsection{Quantitative comparison of spectral albedo data}

The evaluation of the agreement between model and observations depends on the viewpoint chosen. For the spectral albedo, it is convenient to define the quantity $\Delta_{\text {alb }}$, which represents the RMSD between measured and modelled albedo of a given spectrum:

$\Delta_{\mathrm{alb}}=\sqrt{\frac{\sum_{\lambda}\left(\alpha_{\text {meas }, \lambda}-\alpha_{\lambda}\right)^{2}}{N_{\lambda}}}$,

where $\alpha_{\text {meas, } \lambda}$ and $\alpha_{\lambda}$ are respectively the measured and simulated spectral albedo and $N_{\lambda}$ is the total number of considered wavelength ranges. $\Delta_{\text {alb }}$ is expressed in albedo units (i.e. unitless) and can be computed for each date over a chosen wavelength range.

Since the solar incoming radiation is unevenly distributed over the solar spectrum, it is also relevant to compute the difference between model and observations in terms of broadband energy absorbed by the snowpack. In order to do that, we define a second quantity, named $\Delta_{\mathrm{en}}$ :

$\Delta_{\mathrm{en}}=\int_{\lambda}\left(1-\alpha_{\lambda}\right) I_{\lambda} \mathrm{d} \lambda-\int_{\lambda}\left(1-\alpha_{\text {meas }, \lambda}\right) I_{\lambda} \mathrm{d} \lambda$,

where $I_{\lambda}$ is the solar irradiance, obtained by multiplying the broadband incoming short-wave radiation at 11:00 LT by the irradiance spectral distribution. The former was measured using a Li-Cor photodiode and the latter was calculated for a typical Arctic summer atmospheric profile using SBDART (Santa Barbara DISORT Atmospheric Radiative Transfer, Ricchiazzi et al., 1998). $\Delta_{\text {en }}$ is expressed in $\mathrm{Wm}^{-2}$ and can also be computed in percent of the absorbed energy.

\section{Results}

\subsection{Field measurements}

We obtained, in all, 19 workable simultaneous measurements of snow physical and chemical properties and albedo, from 16 May to 25 June 2011. During that period, the characteristics of the snowpack changed. Figure 6 shows the main snow types observed during our field campaign, together with some of their properties. The surface layer was often made up of precipitation particles, such as stellar dendrites (33\% of the days) or columns (11\%). The formation of rime and surface hoar crystals was also frequent (11 and $34 \%$ of the days, respectively). The rest of the time, well sintered rounded grains were dominant at the surface. Deeper, down to $60-80 \mathrm{~cm}$, the snowpack was generally a layered system of hard wind slabs interspersed with faceting rounded grains. Near surface layers of such crystals may further transform into depth hoar, given adequate conditions which include an elevated temperature gradient. This has been reported to happen in summer (Alley et al., 1990). From hand-lens inspections of crystals in the field, typical grain sizes were between 0.4 and $0.8 \mathrm{~mm}$ for faceting rounded grains and about $0.2 \mathrm{~mm}$ for wind-packed particles. The average density of the top $50 \mathrm{~cm}$ was $\sim 330 \mathrm{~kg} \mathrm{~m}^{-3}$, with values ranging from $130 \mathrm{~kg} \mathrm{~m}^{-3}$ for the surface hoar to more than $400 \mathrm{~kg} \mathrm{~m}^{-3}$ for the wind slabs. These results are similar to those obtained by Albert and Shultz (2002) in June 2000. The snow SSA varied between 50 to $70 \mathrm{~m}^{2} \mathrm{~kg}^{-1}$ (corresponding to an optical radius of 47 to $65 \mu \mathrm{m})$ at the surface when fresh snow, rime or surface hoar were present, and about $20 \mathrm{~m}^{2} \mathrm{~kg}^{-1}$ (corresponding to an optical radius of $160 \mu \mathrm{m}$ ) for layers deeper than $60 \mathrm{~cm}$. To address the issue of the hypothetical presence of a high SSA layer at the very surface (Grenfell et al., 1994), several tests were performed. On 16 June, for instance, $0.2 \mathrm{~cm}$ of rime were present at the snow surface. The SSA of the top $\mathrm{cm}$, including this thin rime layer and about $0.8 \mathrm{~cm}$ of faceted 

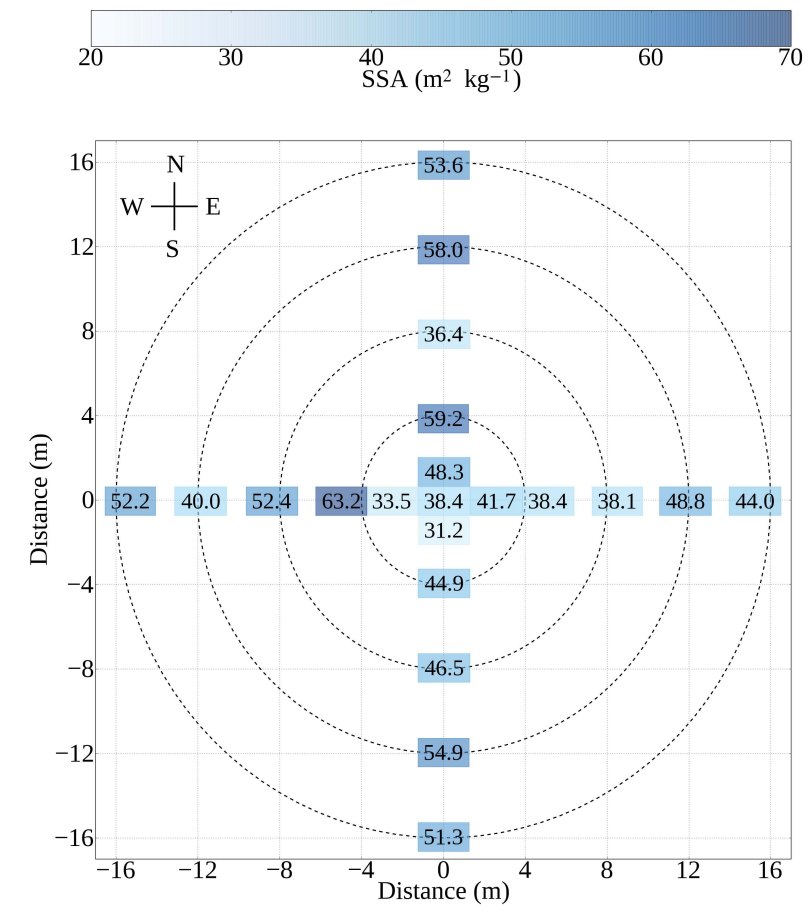

Fig. 7. Spatial variability of SSA in the top $1 \mathrm{~cm}$, measured during the survey of 15 May.

rounded grains, was $51 \mathrm{~m}^{2} \mathrm{~kg}^{-1}$, as measured by presenting the surface layer to DUFISSS. Removing rime and sampling from 0.2 to $1.2 \mathrm{~cm}$ depth gave a slightly lower SSA value, $45 \mathrm{~m}^{2} \mathrm{~kg}^{-1}$. The value obtained by carefully sweeping rime directly in the sample holder was $68 \mathrm{~m}^{2} \mathrm{~kg}^{-1}$. Analogous results were found for other dates: all show that the SSA of the top few mm never exceeded $70 \mathrm{~m}^{2} \mathrm{~kg}^{-1}$, whether this thin layer was made up of precipitation particles, rime or surface hoar crystals. These tests on the SSA of the first few mm were not performed every day; for most of the dates we only know the weighted average of the snow SSA over about a $1 \mathrm{~cm}$ depth.

At Summit, the surface snow layer can display a significant horizontal variability. A spatial survey on 15 May, whose results are shown in Fig. 7, allowed to quantify this variability for the top-cm SSA. These measurements indicate that $1 \mathrm{~m}$ away from the central location SSA can vary by $26 \%$, while $4 \mathrm{~m}$ away this variation can reach $63 \%$.

Figure 8 shows two profiles of the physical properties of snow, for 5 May and 15 June. Both profiles are dominated by faceting rounded grains, with density ranging from 280 to $350 \mathrm{~kg} \mathrm{~m}^{-3}$ and SSA ranging from 20 to $35 \mathrm{~m}^{2} \mathrm{~kg}^{-1}$. Less dense higher-SSA surface layers (precipitation particles, surface hoar, rime) and denser lower-SSA wind slabs were always thinner than $1 \mathrm{~cm}$. Therefore, our snow density profiles, measured with a vertical resolution of about $4 \mathrm{~cm}$, were almost constant along the top $80 \mathrm{~cm}$, whereas the SSA, measured with a vertical resolution of about $1 \mathrm{~cm}$, showed a greater vertical variability, with higher values at the surface. In addition, the data reveal that SSA decreased over time, while density increased slightly. More precisely, our first 8 profiles, from 5 May to 19 May, show, between 2 and $15 \mathrm{~cm}$ deep, a SSA mean value of $37 \pm 3 \mathrm{~m}^{2} \mathrm{~kg}^{-1}$ and a density mean value of $315 \pm 13 \mathrm{~kg} \mathrm{~m}^{-3}$. These values become respectively $23 \pm 3 \mathrm{~m}^{2} \mathrm{~kg}^{-1}$ and $335 \pm 20 \mathrm{~kg} \mathrm{~m}^{-3}$ for our last 8 profiles (11-25 June). This evolution of the snow density and the grains size is a seasonal process that can be visible with a downward periodicity of about $65 \mathrm{~cm}$, the yearly accumulation at Summit (Dibb and Fahnestock, 2004).

During May and June 2011, the BC content measured over the first $1-3 \mathrm{~cm}$ of the snowpack varied from 0.03 to $1.23 \mathrm{ngg}^{-1}$, with a mean value of $0.3 \pm 0.3 \mathrm{ngg}^{-1}$. These results are consistent with previous investigations (Hagler et al., 2007a). The concentration of dust in the upper $1-3 \mathrm{~cm}$ is significantly higher than that of $\mathrm{BC}$, ranging from 49 to $310 \mathrm{ng} \mathrm{g}^{-1}$, with a mean value of $138 \pm 69 \mathrm{ng} \mathrm{g}^{-1}$, three times higher than the value given by Steffensen (1997).

\subsection{Numerical modelling}

In this section, the measured spectral albedo is compared to the albedo simulated using DISORT. Three spectra corresponding to three different dates are shown in Fig. 9. On 19 May, the sky was nearly cloudless, with heavy diamond dust precipitation; on 7 June, thin clouds and low wind $\left(4 \mathrm{~m} \mathrm{~s}^{-1}\right)$ were present; on 20 June, the sky was bright. In all cases, regardless of the different weather conditions, differences are generally lower than 0.02 , except around 1430 and $1800 \mathrm{~nm}$, where they reach 0.1 . All the other dates show the same behaviour.

Figure 10 presents a more quantitative comparison between model and observations in terms of $\Delta_{\mathrm{alb}}$ and $\Delta_{\mathrm{en}}$. For each of the 19 spectra, these quantities were computed for three ranges of wavelengths: the visible region (400$750 \mathrm{~nm})$, the infrared region $(750-2200 \mathrm{~nm})$ and the whole spectrum (400-2200 nm). For each range, we considered the case without any impurity (pure snow) and the case in which we added to our simulations the measured concentrations of $\mathrm{BC}$ and dust. These results are provided in the following sections, focusing on one range of wavelengths at a time.

\subsubsection{Visible region of the spectrum $(400-750 \mathrm{~nm})$}

The differences between simulated and measured albedo are smaller at visible wavelengths, compared to the rest of the spectrum: if the DISORT simulations are run with no impurities, $\Delta_{\text {alb }}$ varies between 0.004 and 0.051 , with a median value of 0.018 . Similarly, $\Delta_{\mathrm{en}}$ varies between $-16.62 \mathrm{Wm}^{-2}$ and $0.37 \mathrm{Wm}^{-2}$, with a median value of $-5.58 \mathrm{Wm}^{-2}$, corresponding to $1.03 \%$ of the energy absorbed by the snowpack. If we prescribe the measured BC and dust contents, $\Delta_{\mathrm{alb}}$ and $\Delta_{\text {en }}$ are slightly lower; for example, the median value of $\Delta_{\text {en }}$ becomes $-5.40 \mathrm{Wm}^{-2}$, or $1.01 \%$ of the absorbed energy. 


\section{$05 / 05 / 2011$}

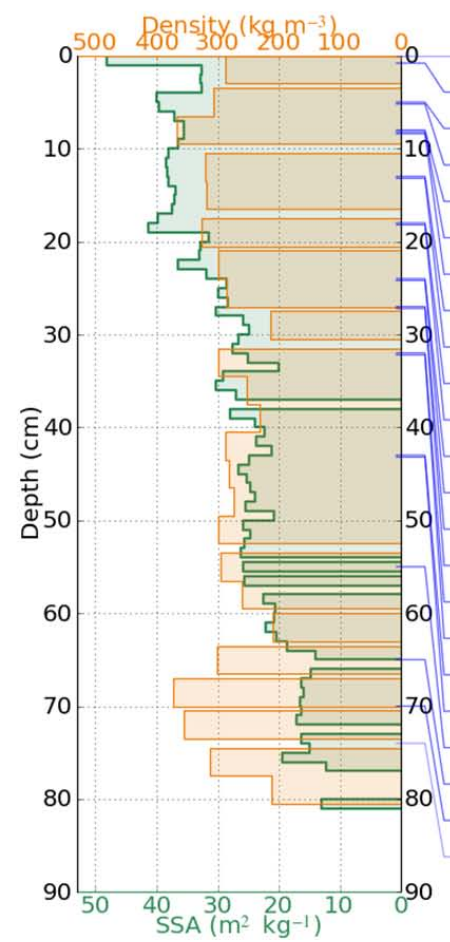

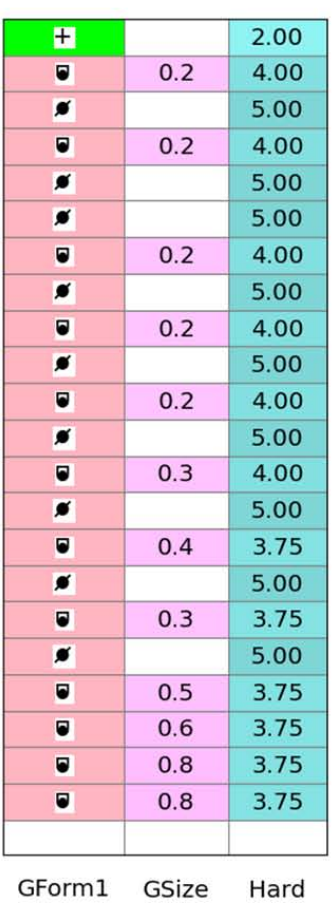

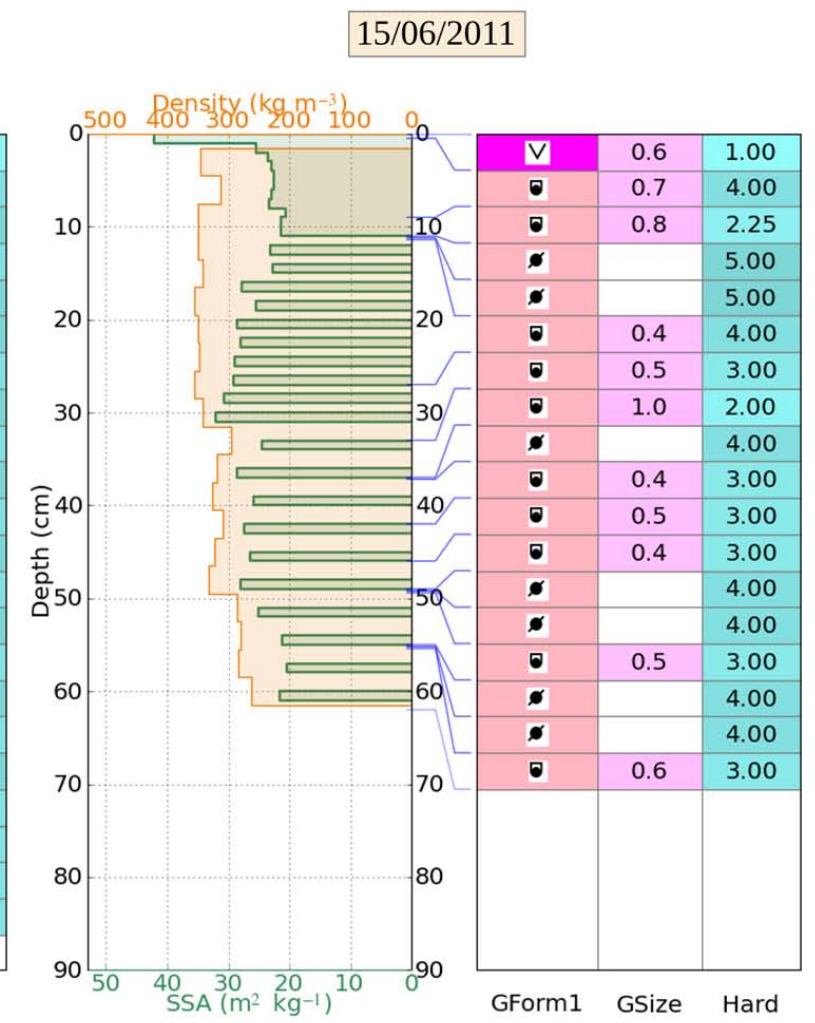

Fig. 8. Vertical profiles of the physical properties of snow, for 5 May (left) and 15 June (right). For each date 2 variables are plotted: orange lines represent density and green lines represent SSA. In the tables, all grain types and sizes (in $\mathrm{mm}$ ) corresponding to the different snow layers are shown, along with the hand hardness.
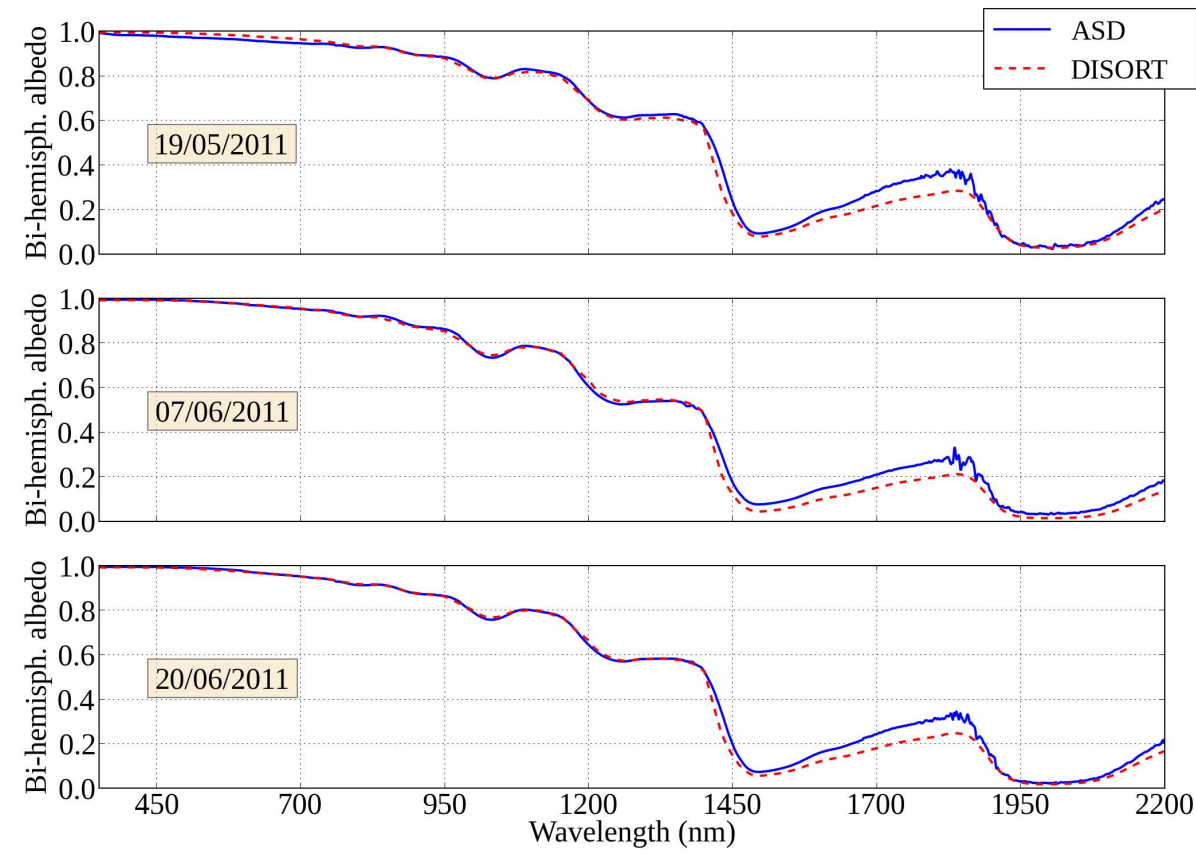

Fig. 9. Measured (solid lines) and simulated (dashed lines) spectral albedo at Summit, for three different dates. 

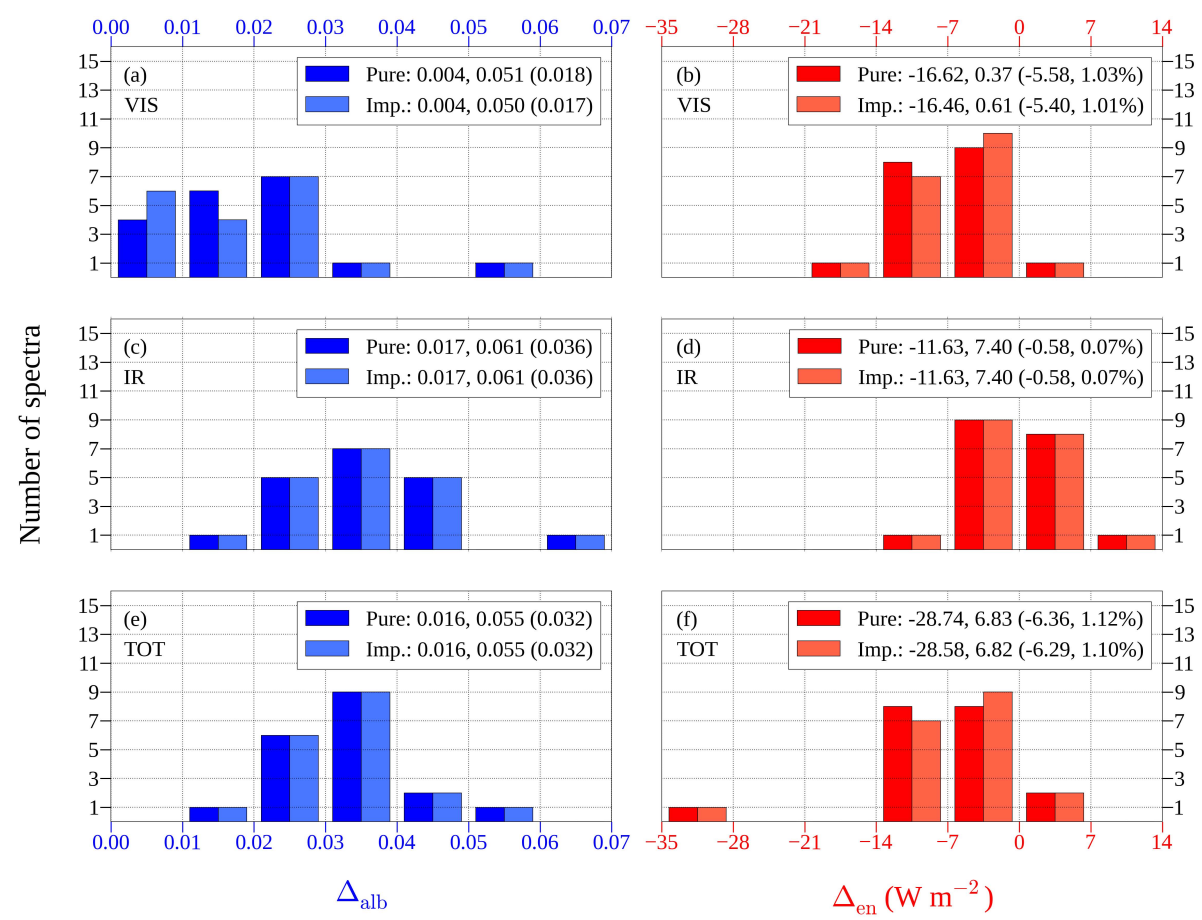

Fig. 10. Comparison between model and observations in terms of $\Delta_{\text {alb }}$ (left panels) and $\Delta_{\text {en }}$ (right panels). Three ranges of wavelengths are considered: the visible (VIS, 400-750 nm) on the top, the infrared (IR, 750-2200 nm) in the middle and the whole spectrum (TOT, $400-2200 \mathrm{~nm}$ ) on the bottom. Histograms show the number of spectra as a function of $\Delta$ values for pure snow and snow contaminated by impurities. The minimum and maximum $\Delta$ values are reported as well, along with the median (in brackets). For $\Delta_{\text {en }}$, the percentages of the energy absorbed by the snowpack corresponding to the median values are also presented.

$\Delta_{\text {en }}$ values obtained in the visible region are systematically negative, meaning that observations are almost always lower than simulations.

Our simulations show that the impact of $\mathrm{BC}$ on the simulated albedo is small, even if the BC is implemented under the assumption of an internal mixing (see Sect. 2.2.2). On 31 May, for instance, we measured a BC content of $0.32 \mathrm{ng} \mathrm{g}^{-1}$ and a dust content of $132 \mathrm{ng} \mathrm{g}^{-1}$; these values are close to the means over the entire campaign. At this date, the diffuse albedo of pure snow at $500 \mathrm{~nm}$ was 0.9929 and the diffuse albedo of snow contaminated by $0.32 \mathrm{ng} \mathrm{g}^{-1}$ of BC over the whole profile was 0.9923 . The impact of dust was about twice as strong, since $132 \mathrm{ng} \mathrm{g}^{-1}$ reduced the albedo to 0.9912 . To obtain the same decrease with only $\mathrm{BC}$, we should have to increase its amount to $0.8 \mathrm{ng} \mathrm{g}^{-1}$. Overall, the coupled effect of dust and $\mathrm{BC}$ remains weak, leading to a decrease of less than $0.2 \%$ in the simulated albedo at $500 \mathrm{~nm}$.

\subsubsection{Near-infrared region of the spectrum (750-2200 nm)}

At the near-infrared wavelengths, like in the visible region, differences are generally lower than 0.02 (see Fig. 9). However, for some wavelengths these differences are higher, up to 0.05 . Obviously, they cannot come from the impurities, since their effect is negligible in this spectral region. The discrepancies can rather be explained by considering the functioning of DUFISSS. As described in Sect. 2.1.4, this instrument allows us to retrieve SSA from infrared reflectance measurements at $1310 \mathrm{~nm}$ and has a vertical resolution of $1 \mathrm{~cm}$. For about half the dates, the disagreement between measured and simulated albedo at $1310 \mathrm{~nm}$ exceeds 0.02 . Since we took great care to handle the surface snow layers (see Sect. 2.1.4), we are confident that we measured the average SSA over the whole first $\mathrm{cm}$ and this difference can be explained by the spatial heterogeneity of the snowpack at Summit. When the agreement between model and observations at $1310 \mathrm{~nm}$ is within 0.02 , instead, differences for longer wavelengths are probably due to our sampling resolution of $1 \mathrm{~cm}$. At the surface, in case of the presence of precipitation particles, rime or surface hoar, the SSA of the first few mm may be higher than that of the whole first $\mathrm{cm}$ (see Sect. 3.1). Then, the upper layer given as input to our simulations, which uses the weighted average of the SSA over $1 \mathrm{~cm}$, may not perfectly reflect the real vertical heterogeneity of the snowpack. For wavelengths greater than $1310 \mathrm{~nm}$, where penetration depth is less than $1 \mathrm{~cm}$, this should result in a slight underestimation of the simulated albedo, because the SSA of the very surface is usually the highest. 


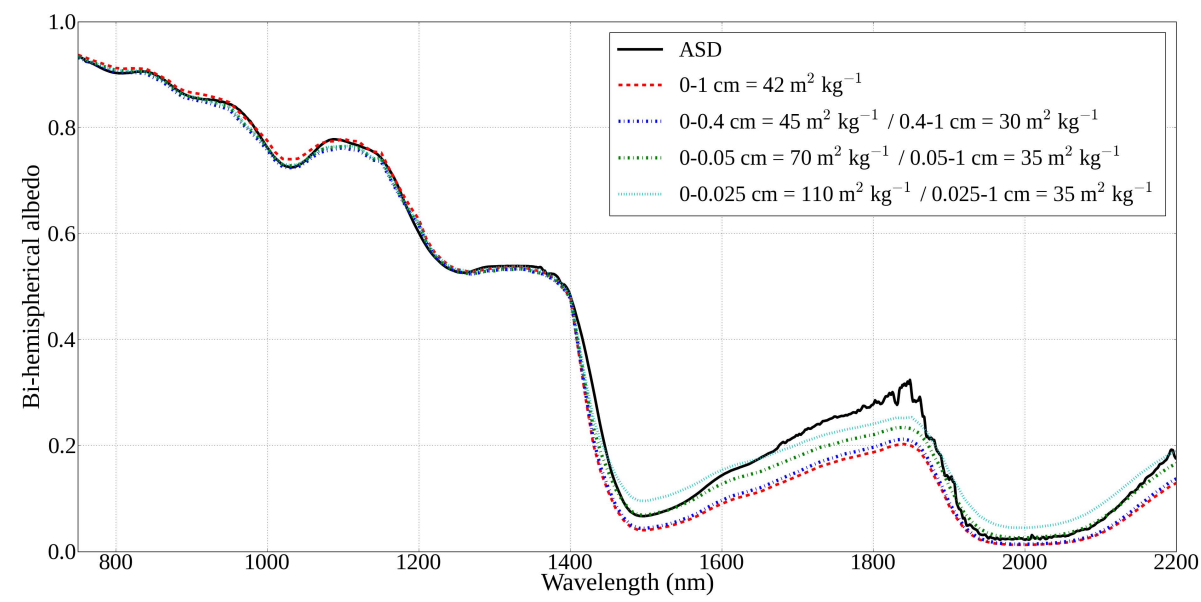

Fig. 11. Impact of the surface layer properties on the simulated albedo at Summit, on 15 June 2011. The black solid line represents the measured albedo and the red dashed line the simulation with experimental data, using in particular the SSA value measured in the first $\mathrm{cm}$ of snow. All the other curves correspond to simulations in which the first $\mathrm{cm}$ was split into two sub-layers and different combinations of thickness and SSA (reported in the legend) were tested: the blue and green dashed-dotted lines represent attempts to match the observed values and the cyan dotted line is the simulation with values from Grenfell et al. (1994).

In order to evaluate the impact of properties of the surface layer on the simulated albedo, we made several tests in which we changed the profiles input into DISORT. In particular, the upper numerical layer ( $1 \mathrm{~cm}$ thick) was divided into two sub-layers: we increased the SSA of the top few $\mathrm{mm}$ and we used a lower SSA for the remaining of the layer, in order to obtain the same albedo value measured by DUFISSS at $1310 \mathrm{~nm}$. Of course, several combinations of SSA and layer thickness can be found. Modifying the density is equivalent to changing the layer thickness: in our simulations, we forced the top sub-layer to $150 \mathrm{~kg} \mathrm{~m}^{-3}$, leaving the other values unchanged. It should be pointed out that these tests only aimed to investigate the influence of the surface layer properties on the modelled albedo; our final simulations and $\Delta$ values (see Sect. 2.3 and Fig. 10) use the original field data. Figure 11 shows an example for 15 June. At that date, the SSA of the first $\mathrm{cm}$ was $42 \mathrm{~m}^{2} \mathrm{~kg}^{-1}$. The model reproduces the observed albedo at $1310 \mathrm{~nm}$ well, but for longer wavelengths it underestimates the observed data, suggesting the presence of a thin, high SSA surface layer. Indeed, as highlighted by the stratigraphy, surface hoar crystals were present at the surface during our SSA measurements. Splitting the first $\mathrm{cm}$ into two sub-layers allows us to reconcile the model with the observations. For example, if we use $30 \mathrm{~m}^{2} \mathrm{~kg}^{-1}$ for the bottom sub-layer, we can have at the surface $0.4 \mathrm{~cm}$ with a SSA of $45 \mathrm{~m}^{2} \mathrm{~kg}^{-1}$. Alternatively, setting the bottom sublayer to $35 \mathrm{~m}^{2} \mathrm{~kg}^{-1}$ can give a thinner surface layer $(0.05 \mathrm{~cm})$ with a SSA of $70 \mathrm{~m}^{2} \mathrm{~kg}^{-1}$; at $1310 \mathrm{~nm}$, both of these combinations reproduce the measured albedo well. Figure 11 also shows the albedo computed by adding a very thin layer of very high SSA, similar to that which Grenfell et al. (1994) had to invoke in order to reconcile their simulations with the spectral albedo measured at the South Pole; in this case, the resulting albedo overestimates the observed data at 1500 and $2000 \mathrm{~nm}$. Similar results were obtained for other dates.

Although changing the surface layer characteristics improves the agreement, it does not allow to overlap model and observations around 1430 and $1800 \mathrm{~nm}$ : there, the discrepancies exceed 0.05 and are found for all the dates, independent of the surface snow properties. This means that, even if we divide the top $\mathrm{cm}$ into two sub-layers, no combination of SSA and layer thickness matching the observed data at these wavelengths can be found. Figure 12 shows, for instance, the difference between measured and simulated albedo on 20 June. This difference is within \pm 0.02 along most of the spectrum, but is greater around 1430 and $1800 \mathrm{~nm}$. To exclude any influence of the ASD spectroradiometer and the RCR themselves on these results, we performed several albedo measurements at Col de Porte, in the French Alps, using another instrument equipped with an integrating sphere (see Sect. 2.1.3). The difference between measured and simulated spectral albedo at Col de Porte on 9 March 2012 is also plotted in Fig. 12. At CdP, the discrepancies around 1430 and $1800 \mathrm{~nm}$ are less strong than at Summit but still present, meaning that instrument bias and snowpack conditions cannot explain all the discrepancies.

We investigated whether errors in the ice index of refraction could explain this behaviour. Figure 13 shows several values of the imaginary part of the ice refractive index $\left(m_{\mathrm{im}}\right)$ available in the literature, for the range $1400-1900 \mathrm{~nm}$ and for different temperatures relevant to this study. Thick grey lines correspond to values inferred to obtain a simulated albedo within \pm 0.02 of the albedo measured at $\mathrm{Col}$ de Porte on 9 March 2012 (see Fig. 12). This spectrum was chosen since it presents a nearly perfect agreement with the modelled albedo between 1200 and $1300 \mathrm{~nm}$ and between 


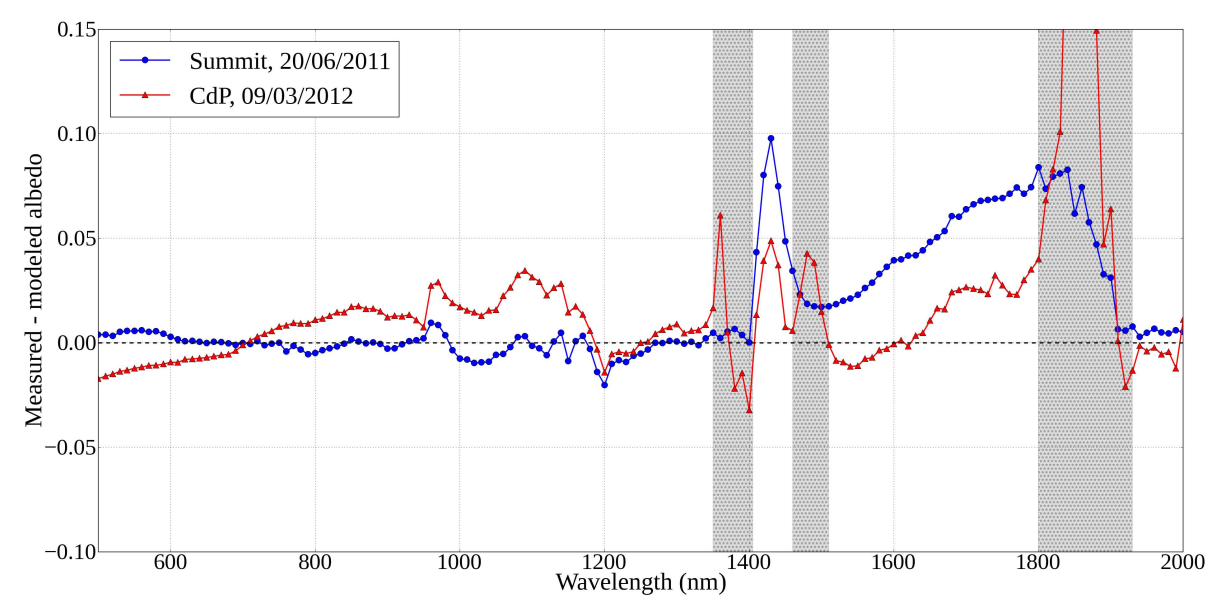

Fig. 12. Differences between measurements and simulations at Summit, on 20 June 2011 (blue circles) and at Col de Porte, on 9 March 2012 (red triangles). Grey vertical bands correspond to wavelengths at which, at the lower elevation of the CdP, water vapour absorption is so strong that there is no reliable signal for the SVC.

1500 and $1600 \mathrm{~nm}$. Regions with no data correspond to wavelengths for which the signal to noise ratio of the device is too low (as grey bands in Fig. 12). For most wavelengths, $m_{\mathrm{im}}$ from Warren and Brandt (2008) is located inside the measured range of variation. Around $1430 \mathrm{~nm}$ and between 1680 and $1800 \mathrm{~nm}$, the ice index from Warren and Brandt (2008) is outside this range. At $1430 \mathrm{~nm}$, no compilation reproduces the measured values well, the best being, in any case, Kou et al. (1993) and Grundy and Schmitt (1998). Warren (1984) and Grundy and Schmitt (1998) seem to better match the observations between 1680 and $1800 \mathrm{~nm}$. Similarly, the same comparison made on the albedo measured at the South Pole from Fig. 4 in Grenfell et al. (1994) reveals that simulated and measured albedo are in better agreement around $1800 \mathrm{~nm}$ using $m_{\text {im }}$ values from Warren (1984) than using those from Warren and Brandt (2008).

\subsubsection{Whole spectrum $(400-2200 \mathrm{~nm})$}

Going back to Fig. 10, we now look at the whole spectrum (400-2200 nm). Just as in the visible region, the best results (i.e. the lowest $\Delta$ absolute values) are obtained using the measured concentrations of impurities; in this case, $\Delta_{\text {en }}$ varies between $-28.58 \mathrm{Wm}^{-2}$ and $6.82 \mathrm{Wm}^{-2}$, with a median value of $-6.29 \mathrm{Wm}^{-2}$. The addition of impurities leads only to a small improvement in our ability to predict the energy absorbed by the snowpack over the whole spectrum, which can be estimated with an accuracy of $1.12 \%$ in case of pure snow and $1.10 \%$ in case of contaminated snow.

Since the simulations have as input the vertical profile of the snow physical properties and the incidence angle of the solar radiation, it is interesting to evaluate the impact of the measurement accuracy of these variables on the simulated albedo. The estimated accuracies of the density sampler and the DUFISSS device are about $\pm 10 \%$, while a variation of $\pm 5^{\circ}$ in the SZA can mimic the effect of the surface roughness on the bi-hemispherical albedo. In Fig. 14, we compared the albedo measured on 20 June to that simulated by varying the SZA, the density and the SSA. Results indicate that these variations have only a negligible impact in the visible region of the spectrum: here, the RMSDs between the albedo simulated with the measured SZA, density and SSA and that computed by varying these values of $\pm 10 \%$ are less than 0.002 . In the infrared wavelengths, however, the impact of the SZA and SSA accuracies is more significant, giving RMSDs ranging from 0.010 to 0.014 , which are of the same order of mag-

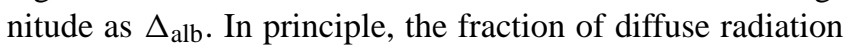
can also influence the albedo. However, considering the fact that during our field measurements the SZA varied between 49 and $52^{\circ}$ and that the diffuse radiation has an effective angle of about $50^{\circ}$ (Wiscombe and Warren, 1980), in our case the accuracy of the diffuse ratio has almost no impact on the simulated albedo.

\section{Discussion}

In this work, the snow spectral albedo measured at Summit (Greenland) was compared to the albedo computed from the snow density and specific surface area profiles and the impurities' concentrations, using the DISORT radiative transfer model.

In the visible region of the spectrum $(400-750 \mathrm{~nm})$, the simulated spectral albedo has a satisfactory agreement with the observed values, even without taking into account the impurities. Indeed, assuming that the snow is completely pure, $\Delta_{\text {alb }}$ has a median value of 0.018 and $\Delta_{\text {en }}$ has a median value of $-5.58 \mathrm{Wm}^{-2}$, corresponding to $1.03 \%$ of the energy absorbed by the snowpack. This means that, even if in principle we have to know the impurity content to correctly simulate the spectral albedo, in practice in our case the addition of 

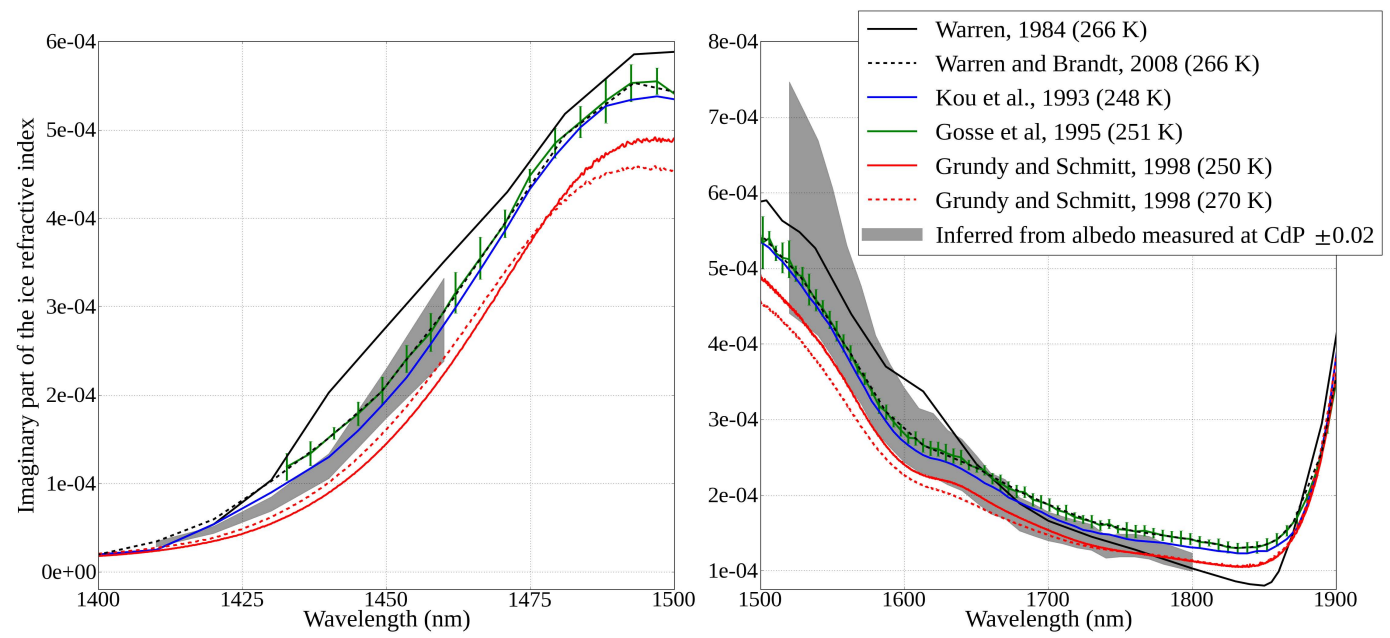

Fig. 13. Imaginary part of the ice refractive index from the literature and inferred from our albedo measurements. Several compilations are presented: Warren (1984) at $266 \mathrm{~K}$ (black solid line), Warren and Brandt (2008) at $266 \mathrm{~K}$ (black dashed line), Kou et al. (1993) at 248 K (blue solid line), Gosse et al. (1995) at $251 \mathrm{~K}$ (green solid line with error bars, as reported in their study), Grundy and Schmitt (1998) at 250 K (red solid line) and $270 \mathrm{~K}$ (red dashed line). Thick grey lines correspond to the values of the refractive index needed to obtain a simulated albedo within \pm 0.02 of our measurements at Col de Porte (see Fig. 12).
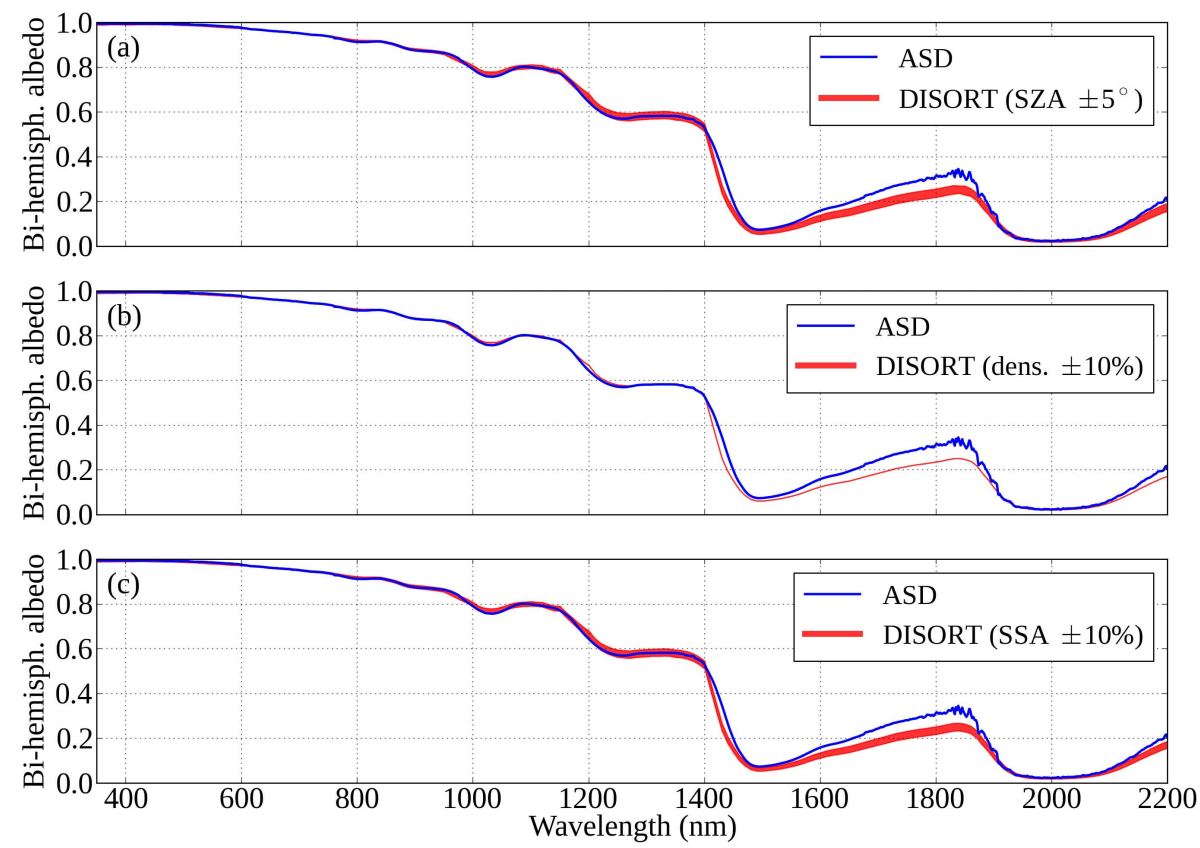

Fig. 14. Measured and simulated albedo at Summit, on 20 June 2011. (a) Impact of a variation of $\pm 5^{\circ}$ in SZA. (b) Impact of a variation of $\pm 10 \%$ in density. (c) Impact of a variation of $\pm 10 \%$ in SSA.

impurities only slightly improves the accuracy of our simulations. This is particularly true for the $\mathrm{BC}$, whose impact on the simulated albedo is negligible due to its very low amount. Since the dust content is about 400 times higher than that of $B C$, its effect is more important. However, the coupled effect of dust and $\mathrm{BC}$ remains weak, leading to a decrease of only $0.2 \%$ in the modelled albedo at $500 \mathrm{~nm}$. The fact that dust, due to its higher concentration, may have a stronger effect on light absorption than $\mathrm{BC}$ is consistent with previous studies in other areas of the world. Wang et al. (2013), for instance, found that in inner Mongolia BC is responsible for only about a third of total particulate light absorption, and in the Qilian Mountains (north of Tibetan Plateau) snow absorption is strongly dominated by dust. Gautam et al. (2013) pointed out the importance of dust deposition toward the darkening of the Himalayan snow cover. The weak effect of BC on 
the energy budget of high Asian glaciers was further confirmed by Ming et al. (2012), who estimated that BC deposition causes a mean forcing of only $5 \%$ of the total forcing and therefore is not the major factor impacting the melting of most glaciers in this area. The vertical distribution of the impurity content also has an impact on the computed albedo, albeit it is small; for example, $\Delta_{\text {en }}$ values computed using the measured $\mathrm{BC}$ and dust amounts either for the entire profile or only for the top $2 \mathrm{~cm}$ differ by just $0.02 \mathrm{Wm}^{-2}$. Some discrepancies between model and observations may partially be due to the fact that the optical constants of BC (France et al., 2012) and dust (Balkanski et al., 2007) are uncertain. In addition, we did not consider other types of absorbing impurities, such as brown carbon and organics, that are also present in Summit snowpack (Bergin et al., 1995). In any case, beyond the impact of impurities, we believe that most of the discrepancies come from our albedo measurements, except for the two spectral bands around 1430 and $1800 \mathrm{~nm}$, which are discussed below. Several hypotheses were made in order to correct the raw albedo signal: for instance, the field of view of the instrument was corrected considering a perfectly absorbing observer and the measured upwelling radiation was assumed isotropic. These errors add up and may be responsible for the deviations between measured and simulated spectral albedo in the visible region.

At the near-infrared wavelengths $(750-2200 \mathrm{~nm})$, the difference between model and observations is generally less than 0.02 . The accuracy of radiation and SSA measurements and the effect of surface roughness (mimicked by a variation of $\pm 5^{\circ}$ in the SZA) may account for deviations up to 0.014 . Larger discrepancies, up to 0.05 , can be instead explained by the spatial heterogeneity of the snowpack: even if we took great care to choose an area over the ASD field of view as spatially homogeneous as possible, the horizontal variability at small scales can be responsible for part of the mismatch between calculations and observations. These discrepancies up to 0.05 can also come from the assumption of spherical snow grains made for DISORT simulations, from our sampling protocol and from the functioning of the DUFISSS instrument, which retrieves SSA from infrared reflectance measurements at $1310 \mathrm{~nm}$, where penetration depth is about $1 \mathrm{~cm}$. Indeed, since wind slabs thinner than $1 \mathrm{~cm}$ were present within Summit snowpack, as well as a very thin, high SSA surface layers (see Sect 3.1), a higher resolution in SSA measurements could improve the DISORT simulations. When the disagreement between measured and simulated albedo at $1310 \mathrm{~nm}$ exceeds 0.02 , we can invoke the spatial variability of the snowpack; in this case, our SSA and density measurements were not completely representative of the state of the snow over the ASD field of view. When the agreement at $1310 \mathrm{~nm}$ is within 0.02 , instead, differences for longer wavelengths may be due to the DUFISSS vertical resolution, which does a weighted average of the SSA over $1 \mathrm{~cm}$ and cannot isolate the characteristics of a thinner surface layer; indeed, when precipitation particles, rime or surface hoar are present at the very top surface, prescribing one SSA value over $1 \mathrm{~cm}$ does not account for this vertical heterogeneity and results in an underestimation of the simulated albedo beyond $1310 \mathrm{~nm}$. Several tests were made to investigate the influence of the surface layer properties on the simulated albedo. These tests demonstrate that splitting the first $\mathrm{cm}$ into two sub-layers and prescribing to the top one reasonable thickness, density and SSA values improves the overall agreement. This also allows to make another interesting remark. At the South Pole, Grenfell et al. (1994) were forced to add to their simulations a thin surface layer $(0.25 \mathrm{~mm})$ with very small grains (SSA of $\left.110 \mathrm{~m}^{2} \mathrm{~kg}^{-1}\right)$ in order to match the albedo observations. At Summit, instead, we do not need to invoke the presence of this very high SSA surface layer to reconcile the discrepancies. Indeed, in our case the SSA values needed for a good matching are never larger than $70 \mathrm{~m}^{2} \mathrm{~kg}^{-1}$ (see Fig. 11). This is further confirmed by our SSA measurements obtained by carefully sweeping surface grains, such as rime or surface hoar, directly in the sample holder; none of these measures gave values beyond $70 \mathrm{~m}^{2} \mathrm{~kg}^{-1}$. Grenfell et al. (1994) stated that in the Antarctic the presence of very small grains at the surface is plausible because of the prevalence of wind drifting. Furthermore, as wind-drifted snow settles when the wind speed diminishes, the smallest suspended grains would be expected to fall out last; thus, even aged snow can have significantly smaller grains at the surface. Our data indicate that at Summit this process probably does not take place.

Around 1430 and $1800 \mathrm{~nm}$, the discrepancies between measured and computed albedo exceed 0.05 and the model clearly underestimates the observed values. At these wavelengths, the differences cannot be due to the snow properties, since changing the surface layer characteristics does not allow to match model and observations. We also excluded that they came from the ASD device itself, since albedo measurements performed in the French Alps with another spectroradiometer gave similar results. Briefly, the difference between measured and simulated albedo at these wavelengths is systematic and does not depend on the input stratigraphic profiles nor on the instrument used to measure the albedo. Our explanation is that these discrepancies are mostly induced by the uncertainty on the value of the ice refractive index. In our simulations we used the most recent compilation of this index (Warren and Brandt, 2008), but Fig. 13 provides evidence favouring Kou et al. (1993) and Grundy and Schmitt (1998) at around $1430 \mathrm{~nm}$ and Warren (1984) and Grundy and Schmitt (1998) at around $1800 \mathrm{~nm}$. Even if at these wavelengths the energy is weak compared to that involved in the visible, a more thorough study of the ice refractive index could be helpful, not only to interpret the data presented here, but also for remote sensing retrieval of snow properties. 


\section{Conclusions}

We present in this work the results of a two-month field campaign at Summit, Greenland. In May and June 2011, we performed simultaneous, co-located measurements of the snow spectral albedo and the snow physical properties, in particular the density and the specific surface area (SSA). To evaluate the impact of particulate absorbers in snow, we also collected samples for chemical analyses including dust and black carbon (BC). The measured snow spectral albedo data were then compared to the albedo computed from the snow physical and chemical properties using the DISORT radiative transfer model. The ability of this model to simulate the albedo was tested, investigating the effects of $\mathrm{BC}$ and dust in the visible wavelengths and describing some possible sources of discrepancies between simulated and measured albedo in the near-infrared region.

DISORT has proven capable of reproducing accurately the albedo measurements; overall, our results indicate that the snow SSA and density can be used to infer the broadband energy absorbed by the snowpack within $1.12 \%$. Taking into account snow particulate absorbers makes it possible to reach an accuracy of $1.10 \%$, meaning that the addition of impurities only slightly affects our results, due to their low concentrations at Summit. Minor deviations present in the nearinfrared (up to 0.014) can be due to the accuracy of radiation and SSA measurements and to the surface roughness, whereas deviations up to 0.05 can be explained by the vertical resolution of measurements of surface layer physical properties, the spatial heterogeneity of the snowpack at small scales and the assumption of spherical snow grains made for DISORT simulations. At 1430 and around $1800 \mathrm{~nm}$, the discrepancies exceed 0.05 and are found to be independent of the snow properties and the instrument used. They may be due to the uncertainties on the ice refractive index at these wavelengths.

In the near future, this modelling framework will allow the evaluation of physically based albedo schemes in detailed snowpack models. Also, our study suggests the need of new measurements of the ice refractive index in the infrared region; improved data sets will be used in retrieval algorithms to more accurately estimate snow properties using remote sensing data, e.g. to retrieve surface snow SSA from NIR MODIS bands (Mary et al., 2013).
Acknowledgements. The Summit field work was funded by grant No. 1088 from French Polar Institute (IPEV) to F. Domine, by grant No. 1023227 from National Science Foundation (NSF) to M. Bergin and by grant ARC1022996 from NSF to J. Dibb. We thank 109th Air National Guard and all crew at Summit for logistic support during the field campaign, K. Steffen, N. Bayou and Greenland Climate Network (project sponsored by NASA and NSF) for providing meteorological data and Fondation Eau, Neige et Glace and CNRS for funding the purchase of the SVC spectroradiometer. Additional funding was provided by Agence Nationale de la Recherche (MONISNOW ANR-11-JS56-005-01). The angular response of the RCR was characterized using the RCR provided by D. Perovich and the ASD provided by Norwegian Polar Institute (J.-C. Gallet, S. Gerland). We also want to thank R. Brandt for help with albedo corrections, B. Schmitt for providing ice refractive index data, S. Warren for useful discussions, J.-C. Gallet for help with DISORT and M. Lacroix for help with plotting.

Edited by: S. Gruber

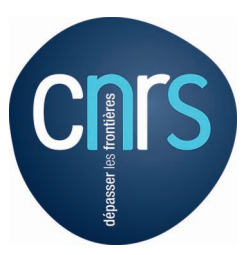

The publication of this article is financed by CNRS-INSU.

\section{References}

Albert, M. and Hawley, R.: Seasonal differences in surface energy exchange and accumulation at Summit, Greenland, Ann. Glaciol., 31, 387-390, 2000.

Albert, M. R. and Shultz, E. F.: Snow and firn properties and airsnow transport processes at Summit, Greenland, Atmos. Environ., 36, 2789-2797, 2002.

Alley, R., Saltzman, E., Cuffey, K., and Fitzpatrick, J.: Summertime formation of depth hoar in central Greenland, Geophys. Res. Lett., 17, 2393-2396, 1990.

Aoki, T., Hachikubo, A., and Hori, M.: Effects of snow physical parameters on shortwave broadband albedos, J. Geophys. Res., 108, 4616, doi:10.1029/2003JD003506, 2003.

Balkanski, Y., Schulz, M., Claquin, T., and Boucher, O.: Reevaluation of mineral aerosol radiative forcings suggests a better agreement with satellite and AERONET data, Atmos. Chem. Phys., 7, 81-95, doi:10.5194/acp-7-81-2007, 2007.

Bergin, M., Jaffrezo, J.-L., Davidson, C., Dibb, J., Pandis, S., Hillamo, R., Maenhaut, W., Kuhns, H., and Makela, T.: The contributions of snow, fog, and dry deposition to the summer flux of anions and cations at Summit, Greenland, J. Geophys. Res., 100(D8), 16275-16288, doi:10.1029/95JD01267, 1995.

Birch, M. and Cary, R.: Elemental carbon-based method for monitoring occupational exposures to particulate diesel exhaust, Aerosol Sci. Tech., 25, 221-241, 1996.

Bourgeois, C. S., Calanca, P., and Ohmura, A.: A field study of the hemispherical directional reflectance factor and spectral albedo of dry snow, J. Geophys. Res., 111, D20108, doi:10.1029/2006JD007296, 2006.

Chýlek, P., Ramaswamy, V., and Srivastava, V.: Dielectric constant of a composite inhomogeneous media, Phys. Rev. B, 27, 5098- 
5106, doi:10.1103/PhysRevB.27.5098, 1983a.

Chýlek, P., Ramaswamy, V., and Cheng, R.: Albedo of sootcontaminated snow, J. Geophys. Res., 88, 10837-10843, 1983 b.

Colbeck, S. C.: Theory of metamorphism of dry snow, J. Geophys. Res., 88, 5475-5482, doi:10.1029/0JGREA0000880000C9005475000001, 1983.

Conger, S. M. and McClung, D. M.: Comparison of density cutters for snow profile observations, J. Glaciol, 55, 163-169, 2009.

Dibb, J. E. and Fahnestock, M.: Snow accumulation, surface height change, and firn densification at Summit, Greenland: Insights from 2 years of in situ observations, J. Geophys. Res., 109, D24113, doi:10.1029/2003JD004300, 2004.

Dibb, J. E., Whitlow, S. I., and Arsenault, M.: Seasonal variations in the soluble ion content of snow at Summit, Greenland : Constraints from three years of daily surface snow samples, Atmos. Environ., 41, 5007-5019, doi:10.1016/j.atmosenv.2006.12.010, 2007.

Doherty, S. J., Warren, S. G., Grenfell, T. C., Clarke, A. D., and Brandt, R. E.: Light-absorbing impurities in Arctic snow, Atmos. Chem. Phys., 10, 11647-11680, doi:10.5194/acp-1011647-2010, 2010.

Domine, F., Salvatori, R., Legagneux, L., Salzano, R., Fily, M., and Casacchia, R.: Correlation between the specific surface area and the short wave infrared (SWIR) reflectance of snow: preliminary investigation, Cold Reg. Sci. Technol., 46, 60-68, doi:10.1016/j.coldregions.2006.06.002, 2006.

Domine, F., Taillandier, A.-S., Houdier, S., Parrenin, F., Simpson, W. R., and Douglas, T. A.: Interactions between snow metamorphism and climate physical and chemical aspects, in: P. C. I., edited by: Kuhs, W. F., 27-46, Roy. Soc. Chem., Cambridge, UK, 2007a.

Domine, F., Taillandier, A.-S., and Simpson, W. R.: A parameterization of the specific surface area of seasonal snow for field use and for models of snowpack evolution, J. Geophys. Res., 112, F02031, doi:10.1029/2006JF000512, 2007b.

Domine, F., Gallet, J.-C., Bock, J., and Morin, S.: Structure, specific surface area and thermal conductivity of the snowpack around Barrow, Alaska, J. Geophys. Res., 117, D00R14, doi:10.1029/2011JD016647, 2012.

Dumont, M., Brissaud, O., Picard, G., Schmitt, B., Gallet, J.-C., and Arnaud, Y.: High-accuracy measurements of snow Bidirectional Reflectance Distribution Function at visible and NIR wavelengths - comparison with modelling results, Atmos. Chem. Phys., 10, 2507-2520, 2010,

http://www.atmos-chem-phys.net/10/2507/2010/.

Ettema, J., van den Broeke, M., van Meijgaard, E., van de Berg, W., Bamber, J., Box, J., and Bales, R.: Higher surface mass balance of the Greenland ice sheet revealed by highresolution climate modeling, Geophys. Res. Lett., 36, L1250, doi:10.1029/2009GL038110, 2009.

Fettweis, X., Tedesco, M., van den Broeke, M., and Ettema, J.: Melting trends over the Greenland ice sheet (1958-2009) from spaceborne microwave data and regional climate models, The Cryosphere, 5, 359-375, doi:10.5194/tc-5-359-2011, 2011.

Fierz, C., Armstrong, R. L., Durand, Y., Etchevers, P., Greene, E., McClung, D. M., Nishimura, K., Satyawali, P. K., and Sokratov, S. A.: The international classification for seasonal snow on the ground, IHP-VII Technical Documents in Hydrology n 83, IACS Contribution n 1, 2009.
Flanner, M., Shell, K., Barlage, M., Perovich, D., and Tschudi, M.: Radiative forcing and albedo feedback from the Northern Hemisphere cryosphere between 1979 and 2008, Nat. Geosci., 2011.

Flanner, M., Liu, X., Zhou, C., and Penner, J.: Enhanced solar energy absorption by internally-mixed black carbon in snow grains, Atmos. Chem. Phys., 12, 4699-4721, doi:10.5194/acp-12-46992012, 2012.

Flanner, M. G. and Zender, C. S.: Linking snowpack microphysics and albedo evolution, J. Geophys. Res., 111, D12208, doi:10.1029/2005JD006834, 2006.

France, J. L., Reay, H. J., King, M. D., Voisin, D., Jacobi, H., Beine, H. J., Anastasio, C., MacArthur, A., and Lee-Taylor, J.: Hydroxyl radical and NOx production rates, black carbon concentrations and light-absorbing impurities in snow from field measurements of light penetration and nadir reflectivity of on-shore and offshore coastal Alaskan snow, J. Geophys. Res., 117, D00R12, doi:10.1029/2011JD016639, 2012.

Gallet, J.-C., Domine, F., Zender, C. S., and Picard, G.: Measurement of the specific surface area of snow using infrared reflectance in an integrating sphere at 1310 and $1550 \mathrm{~nm}$, The Cryosphere, 3, 167 - 182, doi:10.5194/tc-3-167-2009, 2009.

Gallet, J.-C., Domine, F., Arnaud, L., Picard, G., and Savarino, J.: Vertical profile of the specific surface area and density of the snow at Dome C and on a transect to Dumont D'Urville, Antarctica - albedo calculations and comparison to remote sensing products, The Cryosphere, 5, 631-649, doi:10.5194/tc-5-6312011, 2011.

Gardner, A. S. and Sharp, M.: A review of snow and ice albedo and the development of a new physically based broadband albedo parametrization, J. Geophys. Res., 115, F01009, doi:10.1029/2009JF001444, 2010.

Gautam, R., Hsu, N. C., Lau, W. K.-M., and Yasunari, T. J.: Satellite observations of desert dust-induced Himalayan snow darkening, Geophys. Res. Lett., 40, doi:10.1002/grl.50226, 2013.

Giddings, J. and LaChapelle, E.: Diffusion theory applied to radiant energy distribution and albedo of snow, J. Geophys. Res., 66, 181-189, doi:10.1029/JZ066i001p00181, 1961.

Gosse, S., Labrie, D., and Chylek, P.: Refractive index of ice in the 1.4-7.8 microns spectral range, Applied Optics, 34(28), 6582$6586,1995$.

Grenfell, T. and Warren, S.: Representation of a nonspherical ice particle by a collection of independent spheres for scattering and absorption of radiation, J. Geophys. Res., 104, 31697-31709, doi:10.1029/2000JC000414, 1999.

Grenfell, T. C., Warren, S. G., and Mullen, P. C.: Reflection of solar radiation by the Antarctic snow surface at ultaviolet, visible, and near-infrared wavelengths, J. Geophys. Res., 99, 18669-18684, 1994.

Grundy, W. and Schmitt, B.: The temperature-dependent nearinfrared absorption spectrum of hexagonal $\mathrm{H}(2) \mathrm{O}$ ice, J. Geophys. Res., 103, 25809-25822, doi:10.1029/98JE00738, 1998.

Hagler, G., Bergin, M., Smith, E., and Dibb, J.: A summer time series of particulate carbon in the air and snow at Summit, Greenland, J. Geophys. Res., 112, D21309, doi:10.1029/2007JD008993, 2007a.

Hagler, G., Bergin, M., Smith, E., Dibb, J., Anderson, C., and Steig, E.: Particulate and water-soluble carbon measured in recent snow at Summit, Greenland, Geophys. Res. Lett., 34, L16505, doi:10.1029/2007GL030110, 2007b. 
Hall, A.: The role of surface albedo feedback in climate, J. Climate, 17, 1550-1568, 2004.

Hansen, J. and Nazarenko, L.: Soot climate forcing via snow and ice albedos, Proc. Natl. Acad. Sci., 101, 423-428, 2004.

Kokhanovsky, A. and Schreier, M.: The determination of snow specific surface area, albedo and effective grain size using AATSR space-borne measurements, Int. J. Remote Sens., 30, 919-933, doi:10.1080/01431160802395250, 2009.

Kokhanovsky, A. and Zege, E.: Scattering optics of snow, Applied Optics, 43(7), 1589-1602, doi:10.1364/AO.43.0001589, 2004.

Kondratyev, K. and Cracknell, A.: Observing Global Climate Change, Tayler \& Francis Ltd, London, UK, 1998.

Kou, L., Labrie, D., and Chylek, P.: Refractive indeces of water and ice in the 0.65 microns to 2.5 microns spectral range, Appl. Opt., 32, 3531-3540, 1993.

Lemke, P., Ren, J., Alley, R., Allison, I., Carrasco, J., Flato, G., Fujii, Y., Kaser, G., Mote, P., Thomas, R., and Zhang, T.: Observations Changes in Snow, Ice and Frozen Ground, Climate Change 2007: The physical Sciences Basis, 2007.

Lubin, D. and Vogelmann, A. M.: The influence of mixed-phase clouds on surface shortwave irradiance during the Arctic spring, J. Geophys. Res., 116, D00T05, doi:doi:10.1029/2011JD015761, 2011.

Mary, A., Dumont, M., Dedieu, J.-P., Durand, Y., Sirguey, P., Milhem, H., Mestre, O., Negi, H. S., Kokhanovsky, A. A., Lafaysse, M., and Morin, S.: Intercomparison of retrieval algorithms for the specific surface area of snow from near-infrared satellite data in mountainous terrain, and comparison with the output of a semi-distributed snowpack model, The Cryosphere, 7, 741-761, doi:10.5194/tc-7-741-2013, 2013.

Matzl, M. and Schneebeli, M.: Measuring specific surface area of snow by near-infrared photography, J. Glaciol., 52, 558-564, 2006.

Meirold-Mautner, I. and Lehning, M.: Measurements and model calculations of the solar shortwave fluxes in snow on Summit, Greenland, Ann. Glaciol., 38, 279-284, 2004.

Meywerk, J. and Ramanathan, V.: Observations of the spectral clear-sky aerosol forcing over the tropical Indian Ocean, J. Geophys. Res., 104, D20, 24359-24370, 1999.

Mie, G.: Beiträge zur Optik trüber Medien, speziell kolloidaler Metallösungen, Ann. Phys., 330, 377-445, 1908.

Ming, J., Xiao, C., Du, Z., and Yang, X.: An overview of black carbon deposition in High Asia glaciers and its impacts on radiation balance, Adv. Water Resour., doi:10.1016/j.advwatres.2012.05.015, 2012.

Morin, S., Lejeune, Y., Lesaffre, B., Panel, J.-M., Poncet, D., David, P., and Sudul, M.: A 18-years long (1993-2011) snow and meteorological dataset from a mid-altitude mountain site (Col de Porte, France, $1325 \mathrm{~m}$ alt.) for driving and evaluating snowpack models, Earth Syst. Sci. Data, 4, 13-21, doi:10.5194/essd-4-13-2012, 2012.

Nolin, A. W.: Recent advances in remote sensing of seasonal snow, J. Glaciol., 56, 1141-1150, doi:10.3189/002214311796406077, 2011.

Nolin, A. W. and Dozier, J.: A Hyperspectral Method for Remotely Sensing the Grain Size of Snow, Remote Sens. Environ., 74, 207$216,2000$.

Odermatt, D., Schläpfer, D., Lehning, M., Schwikowski, M., Kneubühler, M., and Itten, K.: Seasonal study of directional re- flectance properties of snow, EARSeL eProceedings, 4, 203-214, 2005.

Painter, T. H., Molotch, N. P., Cassidy, M., Flanner, M., and Steffen, K.: Contact spectroscopy for determination of stratigraphy of optical grain size, J. Glaciol, 53, 121-127, 2006.

Pedersen, C. A. and Winther, J.: Intercomparison and validation of snow albedo parameterization schemes in climate models, Clim. Dynam., 25, 351-362, doi:10.1007/s00382-005-0037-0, 2005.

Perovich, D.: Light reflection and transmission by a temperate snow cover, J. Glaciol., 53, 201-210, 2007.

Ricchiazzi, P., Yang, S., Gautier, C., and Sowle, D.: SBDART: A research and teaching software tool for plane-parallel radiative transfer in the earth's atmosphere, in: Bull. Am. Meteorol. Soc., October 1, 1998.

Roman, M., Schaaf, C., Lewis, P., Gao, F., Anderson, G., and Privette, J.: Assessing the coupling between surface albedo derived from MODIS and the fraction of diffuse skylight over spatiallycharacterized landscapes, Remote Sens. Environ., 114, 738-760, 2010.

Stamnes, K., Tsay, S.-C., Wiscombe, W., and Jayaweera, K.: Numerically stable algorithm for discrete-ordinate-method radiative transfer in multiple scattering and emitting layered media, Appl. Opt., 27, 2502-2509, 1988.

Steffen, K., Box, J. E., and Abdalati, W.: Greenland Climate Network: GC-Net, in: Colbeck, S. C. Ed. CRREL 96-27 Special Report on Glaciers, Ice Sheets and Volcanoes, trib. to M. Meier, 98-103, 1996.

Steffensen, J.: The size distribution of microparticles from selected segments of the Greenland Ice Core Project ice core representing different climatic periods, J. Geophys. Res., 102, 26755-26763, doi:10.1029/97JC01490, 1997.

van Meijgaard, E., van Ulft, L., van de Berg, W., Bosveld, F. C., van den Hurk, B., Lenderink, G., and Siebesma, A.: The KNMI regional atmospheric climate model RACMO version 2.1 , Tech. rep., De Bilt, The Netherlands, 2008.

Vionnet, V., Brun, E., Morin, S., Boone, A., Martin, E., Faroux, S., Moigne, P. L., and Willemet, J.-M.: The detailed snowpack scheme Crocus and its implementation in SURFEX v7.2, Geosci. Model. Dev., 5, 773-791, doi:10.5194/gmd-5-773-2012, 2012.

Wang, X. and Zender, C.: Arctic and Antarctic diurnal and seasonal variations of snow albedo from multiyear Baseline Surface Radiation Network measurements, J. Geophys. Res., 116, F03008, doi:10.1029/2010JF001864, 2011.

Wang, X., Doherty, S. J., and Huang, J.: Black carbon and other light-absorbing impurities in snow across Northern China, J. Geophys. Res. Atmos., 118, 1471-1492, doi:10.1029/2012JD018291, 2013.

Warren, S.: Optical properties of snow, Rev. Geophys., 20, 67-89, doi:10.1029/RG020i001p00067, 1982.

Warren, S. and Brandt, R.: Optical constants of ice from the ultraviolet to the microwave: A revised compilation, J. Geophys. Res., 113, D14220, doi:10.1029/2007JD009744, 2008.

Warren, S. G.: Optical contants of ice from the ultraviolet to the microwave, Appl. Opt., 23, 1206-1225, 1984.

Warren, S. G. and Wiscombe, W.: A Model for the Spectral Albedo of Snow. II: Snow Containing Atmospheric Aerosols, J. Atmos. Sci., 37, 2734-2745, 1980. 
Wiscombe, W. J. and Warren, S. G.: A model for the spectral albedo of snow. I: Pure snow, J. Atmos. Sci., 37, 2712-2733, doi:10.1175/1520-0469(1980)037<2712:AMFTSA > 2.0.CO;2, 1980.

Wuttke, S., Seckmeyer, G., and König-Langlo, G.: Measurements of spectral snow albedo at Neumayer, Antarctica, Ann. Geophys., 24, 7-21, doi:10.5194/angeo-24-7-2006, 2006.
Yang, F.: Parameterizing the Dependence of Surface Albedo on Solar Zenith Angle Using Atmospheric Radiation Measurement Program Observations, in: Sixteenth ARM Science Team Meeting Proceedings, Albuquerque, NM, 2006.

Zhuravleva, T. and Kokhanovsky, A.: Influence of surface roughness on the reflective properties of snow, J. Quant. Spectrosc. Radiat. Transfer., 112, 1353-1368, doi:10.1016/j.jqsrt.2011.01.004, 2011. 